\title{
Increasing the Efficiency and Productivity in the Production of Low Voltage Switchboard Using Resource Constrained Project Scheduling
}

\author{
Hendy Tannady (iD), Yona Maimury (iD \\ Industrial Engineering, Bunda Mulia University (Indonesia) \\ bendytannady@yahoo.com,maimury@gmail.com
}

Received: January 2017

Accepted: December 2017

\begin{abstract}
:
Purpose: This research was made with the aim to give a scheduling proposal for the assembly activity and the proposal to allocate those activities into available resources using the resource-constrained project scheduling.

Design/methodology/approach: The research begins with the problem exposition in the existing system on the Assembly Department of panel manufacturer company. To overcome the problem, several scheduling alternatives are formulated to yield better productivity. The performance of proposed system using RCPS is assessed using simulation method. Considering the circumstance of demand rate, the scenarios chosen are based on the parameter such as product departure cycle time, resource utilization, product output, and number of resource required.
\end{abstract}

Findings: The scheduling alternatives provides the better arrangement of work elements in the assembly activity, especially for the product that represent the highest demand rate. For further research, the paper gives encouragement so that the application of RCPS can be used broader in the manufacturing area.

Research limitations/implications: Although the findings were addressed to improve the existing system on the Assembly Department, the practical application haven't been undergone and the performance assessment only based on the simulation method.

Practical implications: By implementing the proposed scheduling, the company will experience several benefits. First, the company could increase its productivity by better utilization of its resources. Second, based on the simulation result, the company could avoid the backorder option while dealing with the high demand rate, and even can fully maximize its resource utilization without adding more worker or apply the overtime policy. Finally, the proposed scheduling that converted into the work instruction could help the company to perform the knowledge transfer from the existing worker or resigned worker to the newly-hired worker.

Originality/value: The outcome of the research could become the guidance for other companies which have similar assembly system to apply the same method. This is the best paper that represents the application of RCPS in the large-sized component assemblies, where the walking worker is responsible for carrying tasks to each unmoved unit.

Keywords: resource-constrained project scheduling, made-to-order, ACTIM, ACTRES, TIMERES, assembly system, simulation 


\section{Introduction}

Nowadays, the rise in wages at the developed country had impacted on the direction of the manufacturing industry development more likely towards the developing country, such as Indonesia. In the developing country, particularly Indonesia, the cheaper wages have made attraction to many foreign investors to open their factory in Indonesia. However, the affordable wages that paid by the company, turned out to be unsupported by the company productivity. From the data provided by Figure 1, it is shown that Indonesia apparently on the quite retarded position in the term of workforce productivity compared with the other neighbourhood country, such as Malaysia, Thailand, and Philippines.

Value Added per Worker (2005 PPP\$*)

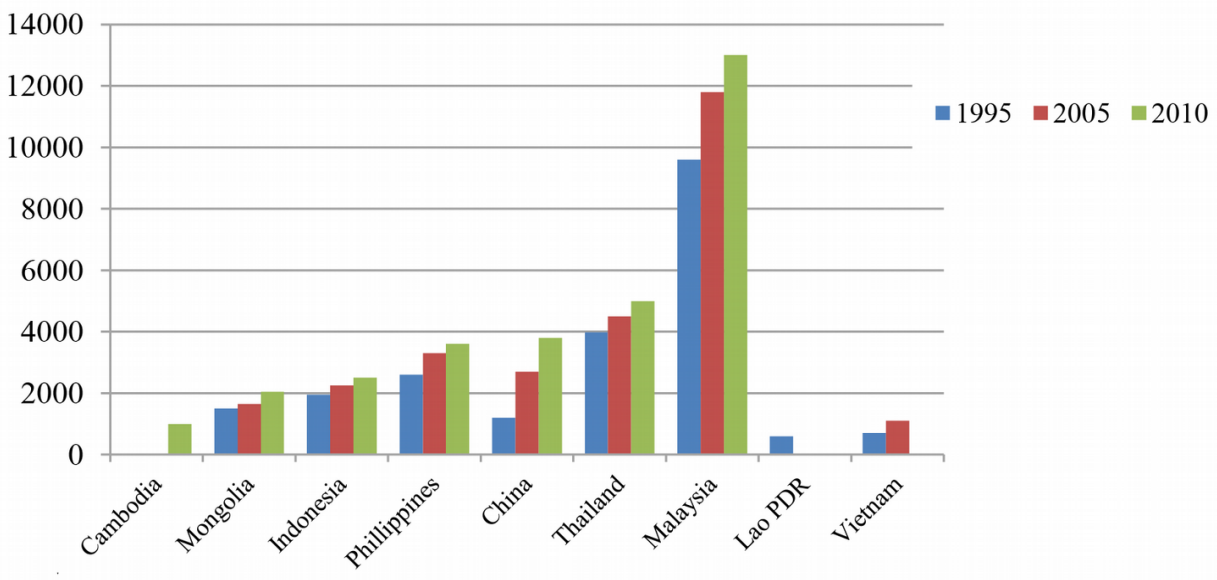

*PPP\$ stand for Purchasing Power Parity in US Dollar

Figure 1. Indonesia Productivity Rate Compared with the Neighborhood Country (World Bank, 2015)

Moreover, a huge number of challenge in the labor intensive company that involving many processing activity as well as manual assembly activity, cause the productivity issue obviously more likely to be encountered. It often causes the query that emerge from the stakeholder, about how to increase the productivity and create a flexible production system to overcome the business trend that rapidly change?

Many previous research have been discussed about efforts to escalate the efficiency and productivity of production process. Naveen and Babu (2015) tried to improve the productivity in manufacturing industry using set of industrial engineering tools, namely bottleneck analysis, Pareto analysis, cause and effect diagram and counter measures. Adnan, Arbaai and Ismail (2016) using line balancing to improve the efficiency of production line, whereas line balancing combined with Yamazumi chart and Takt Time, the other way to improve the efficiency is using lean manufacturing tool (Haragovics \& Miscey, 2014). This research focused on how to increase the efficiency and productivity using the application of resource constrained project scheduling (RCPS).

The research was held in the panel manufacturer and electrical appliance company. In regards to fulfill the customer demand, the company uses the made-to-order production system. During the deadline compliance, especially for the government segment, the company often being forced to choose the backorder option, hire more contract employee, and apply the overtime policy to the permanent employee. It is because the inability of production system to fulfill the existing demand.

Production is carried out according to the agreement that is determined in the beginning through the standard procedure series, by attending the process of tendering (for the government segment). In the production of electrical panel/switchboard, there are consecutive processes, where one of the primary process being done is the assembly activity. The task being executed on the assembly process is distinct and different. In addition, the order of the task is constrained by particular rule, where some of the activities are avoided to be completed foremost before the predecessor activities done. The company offers around 58 variants of electrical panel, therefore its typical assembly system doesn't have similar process, although some of the variant only differ at the voltage level. It causes the assembly system that should be arranged as flexible as 
possible to deal with the demand with high customization rate, with also considers the operation cost, fulfillment of delivery deadline, and available resource.

The planning and arrangement of assembly system should be improved as well as possible under the limited resource of man power, equipment, time, and relationship between subprocess in the assembly activity. The planning could be done by determining the sequence of the tasks, when each task should be done, and how to move between the tasks (Alharkan, 2011). One of the method to actualize the good planning of manufacturing process, by also considering the time and resource limitation is the scheduling method. Scheduling is the method to determine the start and finish time of the collection of process by allocation number of processes into the available resources. Scheduling consists of several tools, which every tools have the different characteristic and being used under different condition. Between them are machine scheduling, flow shop scheduling, job shop scheduling, project scheduling, and so on. (Alharkan, 2011). One of them, project scheduling, is generally used for the project management/construction management planning. Yet as the science is getting more developed, this method then has begun to broaden its application in the manufacturing area, especially to handle the made-to-order as well as engineering to order system production. (Markus, Vancza, Kis \& Kovacs, 2003). As the research done by Kolisch (2006), modelling using RSCP (resource-constrained project scheduling) is applied in the just-in time scheduling for the make-to-order assembly system. This research is also supported by former research with the same topic authored by Agrawal, Harhalakis, Minis and Nagi (1996).

The product with the highest demand according to the historical data owned by the company is the Low Voltage Switch Board 2 Line for Outdoor. This product type consists of sub type product PHB-TR 402 and PHB-TR 252. No significant difference between the two of the subtype product, where the slight difference is only on the Ampere capacity, therefore in this research, the observation is made only at the PHB-TR 252, that automatically be able to represent the PHB-TR 402. Observation is done at one of the subtype of the Low Voltage Switch Board 2 Line for Outdoor, so that the result of this research could facilitate the refinement of the assembly process, particularly for the product with the highest demand based on the historical data for year 2015.

Due to the absence of workload balancing of each operator at assembly department, it causes a high idle rate. Also because of the absence of the standard work procedure explaining the order of assembly job, the assembly flow works ineffectively. Blocking often occurred in between of the operators, which in one product, job processing is done by more than one person with more than 1 work element. However, in another side, it had decreased the speed of certain operator because the process that being done is distracted by another activity. Thus, this condition has become the background of the necessity of the arrangement and scheduling of the work element effectively using the resource-constrained project scheduling method, so that the allocation of the workload for each operator would be balanced and would lead to the increase of productivity and decrement of the backorder rate.

Based on those background, this research was made with the aim to give a scheduling proposal for the assembly activity and the proposal to allocate those activities into available resources using the resource-constrained project scheduling. Some of the scheduling scenario are formulated and the election of the best scenario will be assisted by the method of simulation, through the calculation of idle time, resource utilization, and product departure cycle time.

Several assumptions were made to facilitate the tabulation of data:

1. Because of the uncertain work hour in a week, where the operator sometimes works overtime when the on-going project is dealing with high quantity, therefore the work hour is assumed to be 7 hours per day with total work day in a month is 24 days (including half day work in Saturday)

2. In regards of the simulation execution, the number of demand to predict the system performance is assumed to be similar to the year 2015 .

3. There are some work elements that could be done by 2 or 3 people, where the reduction of completion time is assumed to be linear following the number of operator added. 
This paper is arranged as follows: Begins with the introduction, then continued with the literature review, discussing about the resource constrained project scheduling method, as a method that being used to schedule and allocate the resource for the assembly activity. The next section is research method, methodology, and research object. Then followed by the data collection and tabulation. Finally, the conclusion is discussed with the recommendation for the development of further research and for the concerned company.

\section{Literature Review}

\subsection{Resource-Constrained Project Scheduling (RCPS)}

Resource constrained project scheduling (RCPS) is a scheduling technique that embrace the consideration of the resource limitation, where the predecessor method, that is CPM/PERT only emphasize on the time factor in regards of the project completion. According to Abello and Michalewicz (2014) scheduling as a solution to any RCPS is composed of tasks obeying some precedence relationship, in this method, number of resources of the same type utilized by all ongoing tasks are constrained not to exceed a predefined limit, in dynamic environment, an implemented schedule can turn into an infeasible. RCPS has two primary objectives, those are:

1. Minimize the project time completion (Cmax)

2. Allocate each work element to each resource to achieve the optimum utilization.

The purpose of this scheduling is reached by the well utilization of the resource such as man power, machine, and other physical item that support the execution of the project. Many research being done to yield the solution by using heuristic method for the scheduling case, and some of them had been successfully applied in the real environment. (Alharkan, 2011). This method is adjusted in several categories of case, those are:

1. Single-resource, single-capacity

This category denotes that the available resource only composed from single type of resource, with also single capacity possessed. For example, the company only has a single man that only has a single ability to fix the drilling machine. This case is equivalent to the classical single machine scheduling problem.

2. Single-resource, multiple-capacity

In this type of scheduling, only one type of resource is considered in multiple quantities. For instances, the company has 5 workers with the ability to fix the drilling machine.

3. Multiple-resource, single-capacity

This type of scheduling problem is encountered in the environment where more than one type of resource is available, in a single quantity. The example is the company who had several types of workers, each worker is classified into specific ability, those are fixing drilling machine, using cutting machine, and welding. For each category of those abilities, it only contains one person.

4. Multiple-resource, multiple-capacity

Finally, in the last category, the resource is available for more than one type with more than one capacity possessed. For example, the company has several workers classified into specific skill, those are fixing the drilling machine, using cutting machine, and welding. For each category of those abilities, it contains five persons.

In this research, the literature review is only focusing on the second category, to adjust with the real condition happened in the concerned field. 


\subsection{Single-Resource, Multiple-Capacity RCPS}

In the allocation of the task for the available resource, we should start from defining the rule used to prioritize the work element. This paper uses the ACTIM (Activity Time) rule that derived from the Brooks' Algorithm. The iteration of the ACTIM rule is explained as follow.

1. Construct the AOA (Activity on Arrow) or AON (Activity on Node) diagram. The example is shown by Figure 2 .

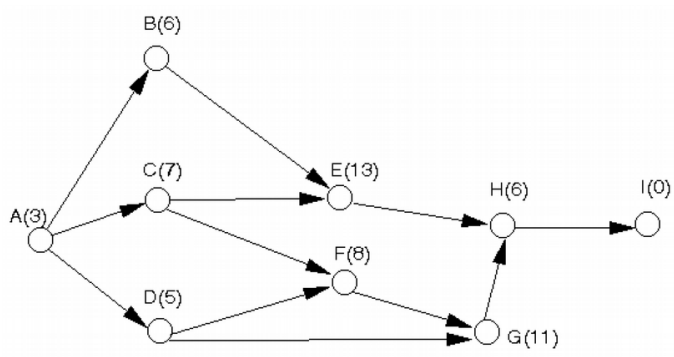

Figure 2. Example of the Activity on Node Diagram

2. Determine for each activity, the maximum time it controls through network, so-called the ACTIM score. The formula of the calculation is as follows:

$$
A C T I M=\text { critical path time }- \text { activity latest start time }
$$

ACTIM (Whitehouse \& Brown, 1979) is one of the earlier activity sequencing rule. The rule was developed by George H. Brooks and used in his algorithm, called Brooks' algorithm (Badiru, 1996). The original algorithm considered only the single project, single resource case, but it lends itself to extensions for the multiresource cases.

Rank the activities in the decreasing order of ACTIM. This order is placed in the uppermost row (see Table 1), where the activity with the highest ACTIM value is on the leftmost. Duration and resource requirement are determined in the early step. The rows TEARL, TSCHED, TFIN, and TNOW are explained as follow: TEARL (early start) is the earliest time of an activity determined by traditional CPM calculation. TSCHED is the actual scheduled starting time of an activity as determined by Brooks' Algorithm. TFIN is the completion time of each activity. And TNOW is the time at which the resource allocation decision is being made.

\begin{tabular}{|l|l|l|l|l|}
\hline Activity & $i=1$ & $i=2$ & $\ldots$ & $i=n$ \\
\hline Duration (days) & & & & \\
\hline ACTIM & & & & \\
\hline Scaled ACTIM & & & & \\
\hline Resource required & & & & \\
\hline TEARL & & & & \\
\hline TSCHED & & & & \\
\hline TFIN & & & & \\
\hline TNOW & & & & \\
\hline Resource available & & & & \\
\hline Activities allowed & & & & \\
\hline Iteration number & & & & \\
\hline
\end{tabular}

Table 1. Heuristic Scheduling Using ACTIM Source: Project Management in Manufacturing and High Technology Operations (Badiru, 1996) 
3. Set TNOW to 0 . The allowable activities to be considered for scheduling at TNOW $=0$ are those activities with TEARL of 0 . These are placed in the activities allowed in the decreasing order of ACTIM. Ties are broken by scheduling the activity with longest duration first.

4. Allocate the resource based on the chosen activity in regards of its ACTIM and TEARL score, input the TSCHED as well as TFIN.

5. Input the TFIN with the closest value to the TNOW that just being filled, at the next TNOW cell.

6. Return to the step 5 and 6 if there are activities that haven't been assigned Otherwise, stop the scheduling.

Beside of the ACTIM rule, this research was also using the ACTRES (Activity Resource) and TIMRES (Time Resource) rule in the case where the activity done by more than one operator, as the comparison for the scheduling result yielded by the ACTIM rule. ACTRES and TIMRES calculation are shown below:

$$
\begin{aligned}
& \text { ACTRES }=\text { Activity time } \times \text { Resource Requirement } \\
& \text { TIMRES }=0,5(\text { ACTIM })+0,5 \text { (ACTRES })
\end{aligned}
$$

The stage after the calculation is similar to the ACTIM step. They differ only in the priority election, where they are based on the ACTRES and TIMRES score rather than ACTIM score.

\section{Research Method}

\subsection{Method}

The method used in this research is the resource-constrained project scheduling. Moreover, the proposal system will be visualized in the ProModel software using the simulation method. The data collection is conducted for 1 month between January 5, 2016 - February 5, 2016.

Research data consists of both primary and secondary data. The collection process of primary data is done by interview and observation, while for the secondary data, collection is done by gathering information through official report issued by the company. Furthermore, to support the process of data processing and analysing, the Author also perform reading activity from the textbook, articles, journal, and other scientific media.

\subsection{Research Methodology}

Research methodology diagram is a flow diagram used to show the procedure sequence being done to assist the achievement of research objective. The methodology is depicted as follows. 


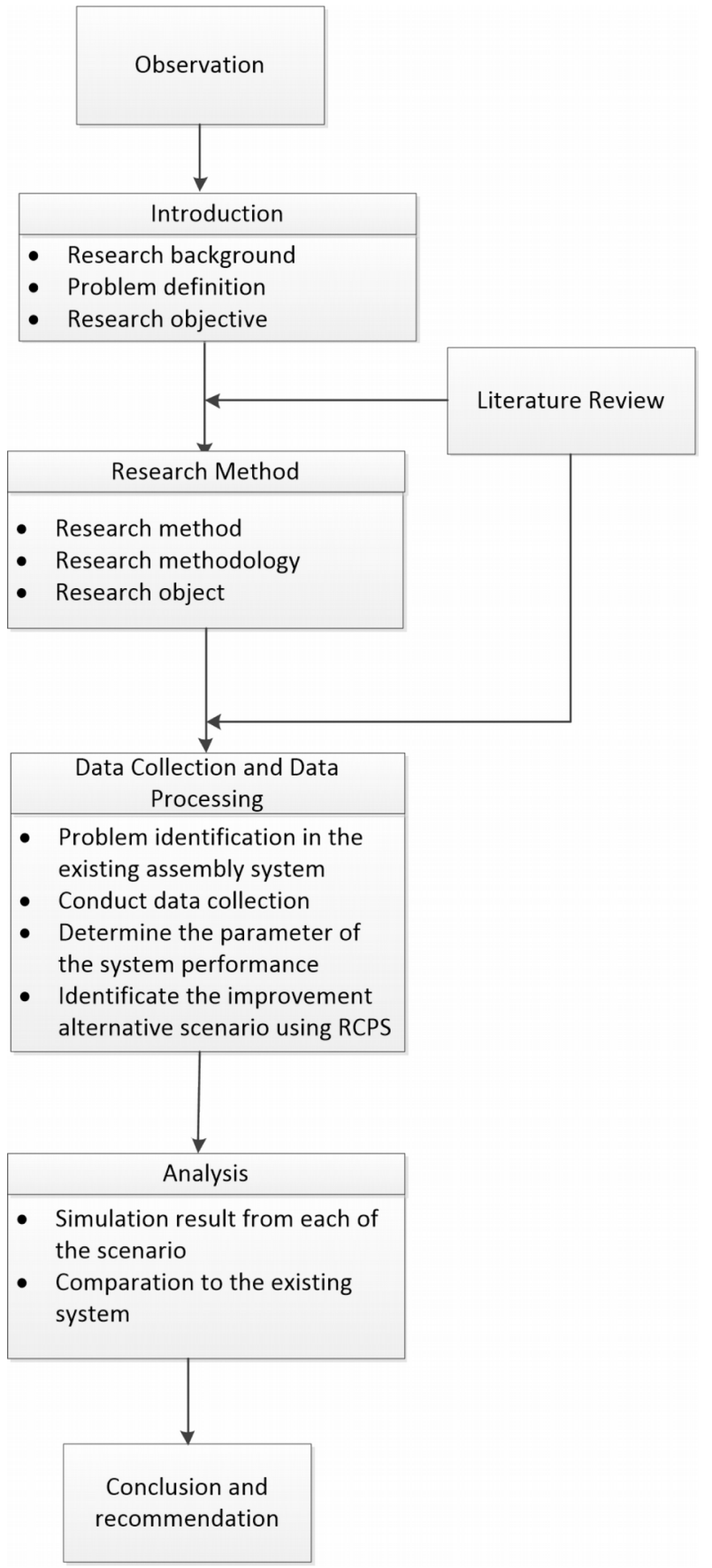

Figure 3. Research Methodology Diagram

\subsection{Research Object}

\subsubsection{Company Overview}

The company is a panel manufacturer and electrical appliances specialist where it serves the provision of national electrical needs, both in the government institution as well as private institution. The company has been established since 1994. The company currently serves the provision of switchboard in the low voltage network and home connection such as: low voltage switchboard for outdoor and indoor, KWH panel Automated Meter Reading, kiosk outdoor for cubicle, trafo, electrical accessories, and others.

Beside of the product mentioned above, the company also offers the electrical needs for the property sector such as: Main Distribution Board, Capacitor Bank, integrated box meter for Mall, Hotel, Apartment, Industry, and so on. Its products are already used widely by electrical national company in Indonesia in many areas across the nation, such as West Java and Banten, East Java, Batam, Bali, Manado, Bangka, and others. The total number of employee is 172 people, consists of 140 people on the factory and 32 people on the headoffice. 


\subsubsection{Assembly Department Overview}

The research is conducted on the Department of Assembly, specifically in the Inkom area, where the assembly of electrical component takes place. Another area under Department of Assembly are CPT Bar and Plating. These are the areas of the supporting activity of the assembly process. CPT Bar is the place where the busbar production being held. The busbar is used in the assembly process at the Inkom area. Fabrication of busbar isn't made based on the demand (push production), but more likely to adapt the made-to-stock production system. It contradicts the Inkom area, where the assembly process occurred is based on the customer order (made-to-order). Another area, Plating, holds the activity of busbar tin coating, so that the busbar will not easily corroded and more solid.

\subsubsection{Switchboard Fabrication Process}

There are series of processes that must be gone through before the product is ready to be delivered. The processes are shown in the diagram below.

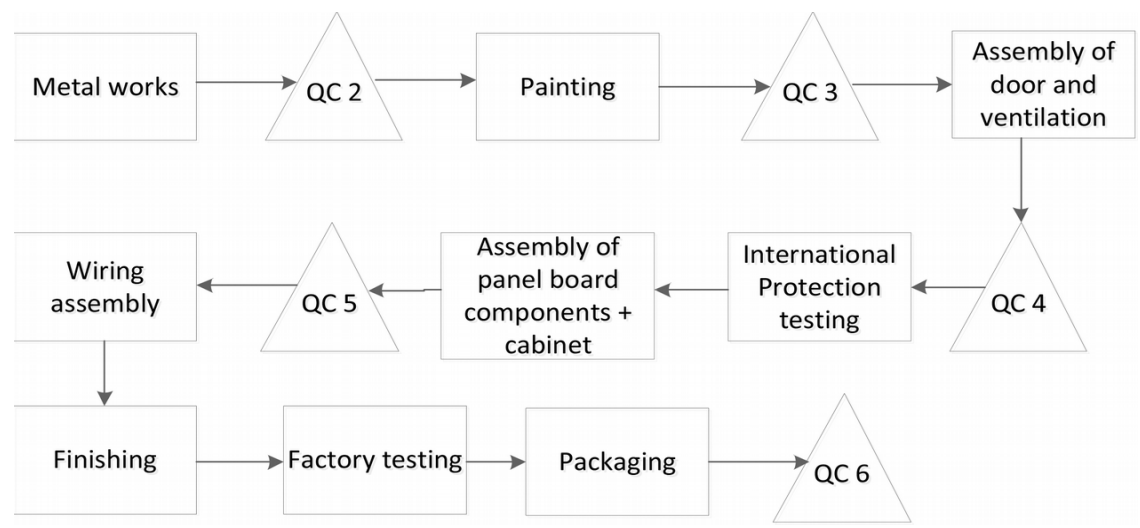

Figure 4. Switchboard Fabrication Process

The process is begun from the metal works, which involving the utilization of heavy machinery, such as cutting, bending, punching, notching, grinding, and welding machine. Most of the activity done in the metal works department is forming the raw material of metal sheet into the shape of ventilation, door, base, and others, to be assembled as cabinet box. Furthermore, the half-finished cabinet box with the supporting accessories is pushed to the quality control inspection (QC2). The first inspection (QC1) itself is the process of checking the conformance of the raw material from the supplier.

After that, it is continued to the painting process. It occurs outside the factory, where the company uses outsourcing service. Generally, before being delivered to the painting process, certain number of half-finished product (batch) is collected. Then, the half-finished boxes along with the supporting accessories will be re-inspected to check its painting quality (QC3). Further, the assembly of door and ventilation to the box then takes place. Again, the quality control is conducted to inspect the quality of the assembly (QC4). Then, boxes is brought to the International Protection Testing area, where the boxes were tested for the anti-leakage. Boxes that didn't pass will be quarantined and fixed, so that it will passed the next test. The boxes that passed the test will be send into the panel board component assembly area. The fifth quality control then takes place and continued to the wiring assembly process. After that, finishing process is conducted to clean up the protrude sheet metal resulted from the cutting process, or the messy paint resulted at the surface area of the box. Furthermore, it leads to the factory testing process, which is the test of the electric current and voltage of the switchboard. After that, the switchboard is covered by plastic wrap and continued to the sixth quality control, and finally is ready to be delivered to the customer.

\section{Data Collection and Tabulation}

\subsection{Work Element of the PHB-TR 252 Assembly Process}

The work element is divided into 26 elements, shown by the table below. 


\begin{tabular}{|c|c|c|}
\hline No & Work element & Information \\
\hline 1 & Clean up the paper tape sticked to the bolt & Per bolt \\
\hline 2 & Assemble the MCCB into the MCCB base & \\
\hline 3 & Insert busbar N M10 bolt & \\
\hline 4 & Assemble the R, S, T, N recolit & Per bolt \\
\hline 5 & Install the connector busbar and busbar tongue into the MCCB & \\
\hline $5-1$ & Busbar tongue installment & \\
\hline $5-2$ & Connector busbar installment & \\
\hline 6 & Insert the busbar $\mathrm{N}$ & \\
\hline 7 & Measure the hole position of busbar R, S & Per busbar \\
\hline 8 & Drill the busbar R, S & Per busbar \\
\hline 9 & Assemble the left side bolt of busbar R, S, T & \\
\hline 10 & Assemble the CT-R, CT-S and CT-T & \\
\hline $10-1$ & Assemble the CT-R and CT-S (including wrap detachment) & \\
\hline $10-2$ & Open the CT-T wrap & \\
\hline $10-3$ & Assemble the CT-T & \\
\hline 11 & Insert the right-side bolt of busbar R, S, T & \\
\hline 12 & Install the MCCB into phase busbar & \\
\hline 13 & Insert the mould to straighten the busbar & \\
\hline 14 & Fasten the M10 connector bolt & \\
\hline 15 & Fasten the MCCB L8 bolt & \\
\hline 16 & Fasten the R, S, T recolit bolt & \\
\hline 17 & Insert the roofing bolt to the MCCB base & \\
\hline 18 & Insert the MCCB valve & \\
\hline 19 & Assemble the fuse rail & \\
\hline $19-1$ & Insert the bolt & \\
\hline $19-2$ & Assemble the fuse rail & \\
\hline $19-3$ & Fasten the bolt manually & \\
\hline 20 & Drilling the busbar tongue recolit hole & \\
\hline 21 & Fasten the fuse rail bolt & \\
\hline 22 & Assemble the busbar tongue recolit & \\
\hline 23 & Assemble the CT fastener & \\
\hline 24 & Insert the busbar tongue M10 bolt & \\
\hline 25 & Fasten the busbar $\mathrm{N}$ and busbar tongue bolt & \\
\hline 26 & Fasten the overall bolt through backside & \\
\hline
\end{tabular}

Note:

- CT (Current Transformer) is used to measure the electric current and monitoring the operation of electric network.

- MCCB is abbreviated from Molded Case Circuit Breaker. Used to cut off and connect the electricity. MCCB will automatically cut off the electricity if there is an electrical fault.

- Fuse rail is called as power distribution protector, because it protects the electrical circuit component from the damage caused by exaggerate electrical current.

- Roofing Bolt is the bolt used to be inserted between MCCB base and main base, so that the MCCB will merge with the main base.

- Phase Busbar is a metallic bar to distribute the power within the electrical system. Consist of busbar R (red), S (yellow), T (black), dan N (blue).

- Recolit is the pad for busbar, so that busbar will not directly touch the main base.

- Busbar Tongue is a small size busbar. Often called as the outgoing busbar.

Table 2. Work element of the PHB-TR 252 Assembly Process 
Work element 5, 10, and 19 have the subordinate elements, that being observed separately. Those subordinate elements, actually can be merged as one element, but considering the field observation where those elements is often conducted separately and sometime interfered by another work element, and even performed by different operator. Therefore, to obtain the cycle time for those element, time record can't be made for the whole activity, instead should be conducted separately.

The 26-work element have their own sequence that form activity series related to each other. Figure 5 shows the precedence rule.

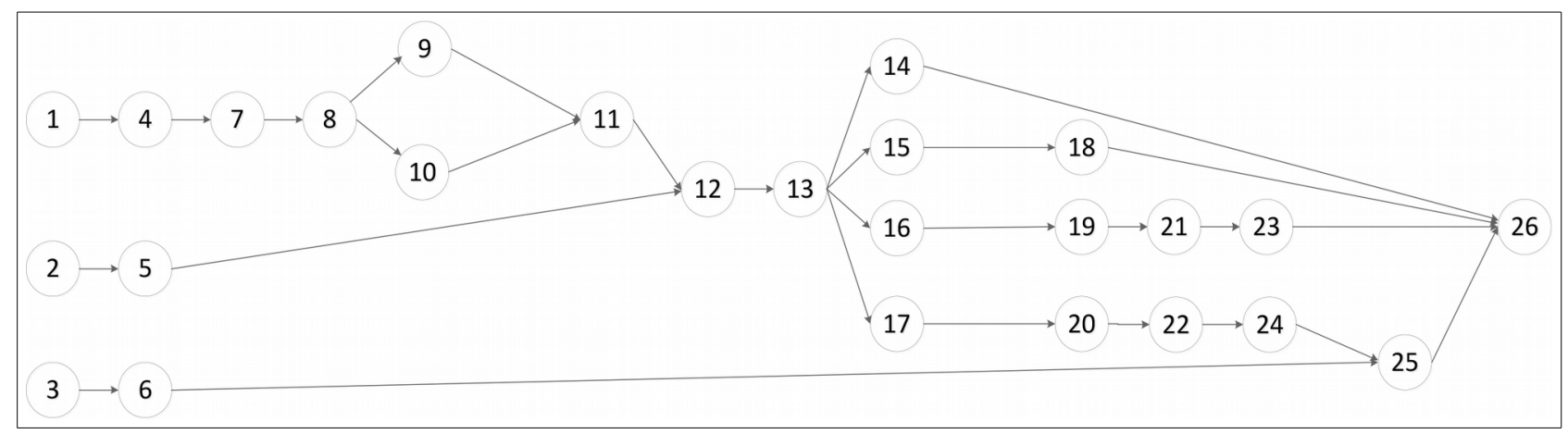

Figure 5. AON for the PHB-TR 252 Component Assembly Process

\subsection{Dimension Data of PHB-TR 252 Electrical Circuit Component}

To obtain a good understanding about the product being assembled, the dimension data of length, breadth, and height from each component was collected. These data also used to determine the allowance and performance rating, so that the standard time from each element would be obtained and well-represent the real condition. The following table show the dimension data.

The following figure provide the general image of the electrical circuit being assembled for the PHB-TR 252.

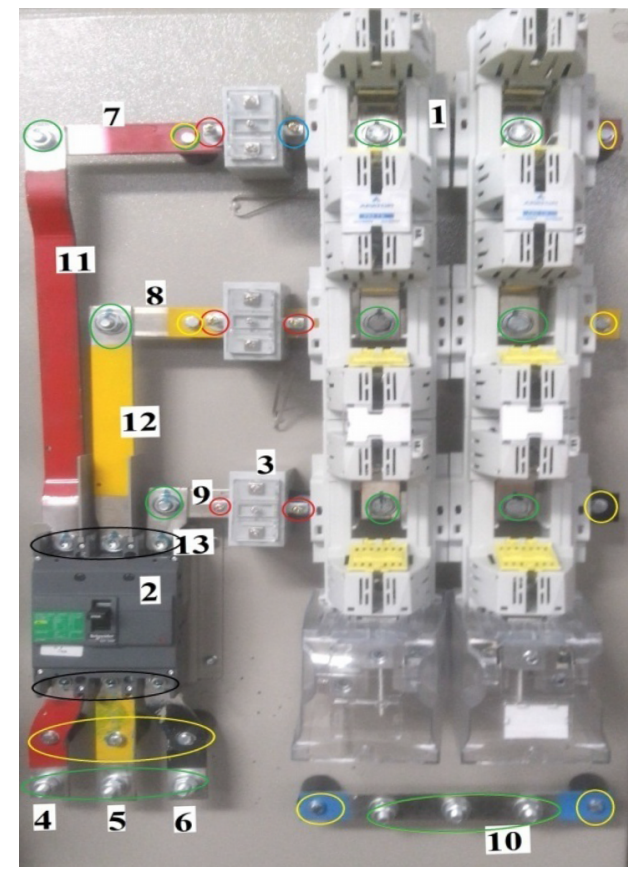

Note: The colour of the mark shows the type of the bolt being used (Refer to Table 2).

Figure 6. PHB-TR 252 Electrical Circuit 


\begin{tabular}{|c|c|c|c|c|c|}
\hline \multirow[b]{2}{*}{ No. } & \multirow[b]{2}{*}{ Name } & \multicolumn{3}{|c|}{ Dimension $(\mathrm{cm})$} & \multirow[b]{2}{*}{ Required unit per base } \\
\hline & & 1 & B & h & \\
\hline 1 & Fuse rail & 68 & 10 & 15 & 2 \\
\hline 2 & MCCB & 17 & 11 & 6 & 1 \\
\hline 3 & Current transformer $250 \mathrm{~A}$ & 7.5 & 4 & 8 & 3 \\
\hline 4 & Busbar tongue $\mathrm{R}$ & 14 & 3 & 5 & 1 \\
\hline 5 & Busbar tongue $\mathrm{S}$ & 14 & 3 & 5 & 1 \\
\hline 6 & Busbar tongue $\mathrm{T}$ & 14 & 3 & 5 & 1 \\
\hline 7 & Phase busbar $\mathrm{R}$ & 43 & 3 & 5 & 1 \\
\hline 8 & Phase busbar S & 39 & 3 & 5 & 1 \\
\hline 9 & Phase busbar $\mathrm{T}$ & 35 & 3 & 5 & 1 \\
\hline 10 & Phase busbar $\mathrm{N}$ & 24 & 3 & 5 & 1 \\
\hline 11 & Connector busbar $\mathrm{R}$ & 43.5 & 3 & 5 & 1 \\
\hline 12 & Connector busbar S & 25 & 3 & 5 & 1 \\
\hline 13 & Connector busbar $\mathrm{T}$ & 7 & 3 & 5 & 1 \\
\hline 14 & CT fastener bolt & & & 3.8 & 3 set \\
\hline 15 & Bolt + Nut + Ring M10 & & & & 15 \\
\hline 16 & Bolt + Nut + Ring M6 & & & & 10 \\
\hline 17 & Bolt + Nut + Ring L8 & & & & 6 \\
\hline 18 & Recolit & & & & 10 \\
\hline 19 & Main base & 100 & 50 & & 1 \\
\hline 20 & MCCB base & 17 & 15 & 1,5 & 1 \\
\hline 21 & MCCB valve & & & & 1 pair \\
\hline
\end{tabular}

Table 3. Dimension of the PHB-TR 252 Electrical Circuit Component

\subsection{Determination of Critical Path and Time for the PHB-TR 252 Assembly Activities}

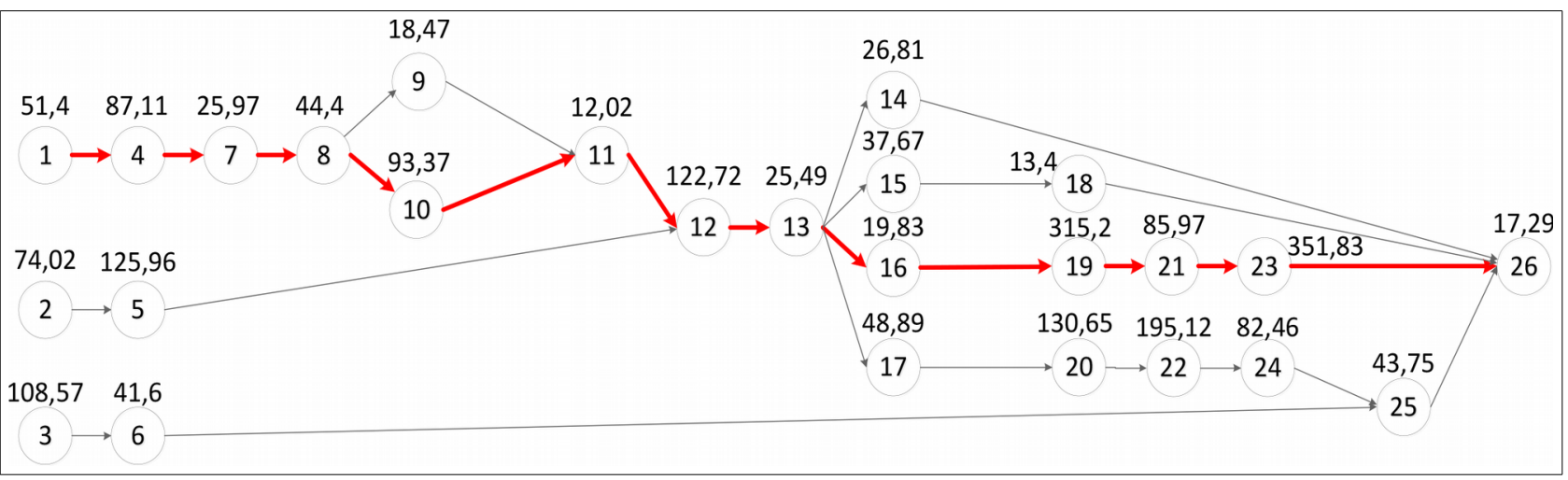

Figure 7. Critical Path Development

Critical path in this research is used as the scheduling reference, where the delay of one work element that part of this critical path, will distract the whole activity completeness time (see Figure 7). The critical time is 1252,6 seconds. It is the minimum duration of completeness time for PHB-TR 252 assembly activity. However, on the next sub section the Author will try to reduce the critical time, by adding more operator at the activity that enabling the additional operator. 


\subsection{Work Element Scheduling Using ACTIM, ACTRES, and TIMRES Rule}

In the made-to-order production system, where the high customization rate along with the relatively low order quantity per type of order per period, RCPS could be applied to arrange the assembly activity of PHB-TR 252 electrical circuit component, by scheduling and allocating work element to the available resource. In the single resource-multiple capacity environment, several methods can be used. Between them are ACTIM (Activity time), TIMRES (Time resource), and ACTRES (Activity Resource). The difference from these three methods is the priority value of each work element. This priority value is used to determine which of the work element required to be firstly assigned if it is possible. If impossible, for example because of there is a precedence activity that hasn't been done yet, then the work element with second highest priority value will be assigned. This priority value itself are ACTIM, ACTRES, and TIMRES (the term of the rule actually refers to the priority value). ACTIM is calculated by subtracting the critical time with the late start value. Whilst, the ACTRES value is obtained by multiplying the ACTIM value with the resource requirement, and finally the TIMRES is calculated by averaging the ACTIM value with the ACTRES value.

To be able to define the ACTIM value, calculation of LS (late start) for each work element should be conducted. This calculation must be simultanously done with the calculation of ES (early start), EF (early finish), and LF (late finish), because those values are interrelated to each other. The following table shows the result of the calculation.

In this research, all the standard time is obtained through the time study process, by adjusting its performance rating and allowance. The standard time on the Table 4 is the completion time of the work element that only performed by one operator, therefore, using ACTRES and TIMRES rule, priority yielded will be the same with ACTIM. However, if several work elements are added, more required resources ACTRES and TIMRES rule could become the comparison of ACTIM rule.

\begin{tabular}{|c|c|c|c|c|c|c|c|}
\hline $\begin{array}{l}\text { Work } \\
\text { Element }\end{array}$ & $\begin{array}{l}\text { Standard } \\
\text { Time }\end{array}$ & ES & $\mathrm{EF}$ & LS & LF & ACTIM & $\begin{array}{l}\text { ACTIM } \\
\text { Rank }\end{array}$ \\
\hline 26 & 17.29 & 1235.31 & 1252.6 & 1235.31 & 1252.6 & 17.29 & 26 \\
\hline 14 & 26.81 & 462.48 & 489.29 & 1208.5 & 1235.31 & 44.1 & 24 \\
\hline 18 & 13.4 & 500.15 & 513.55 & 1221.91 & 1235.31 & 30.69 & 25 \\
\hline 23 & 351.83 & 883.48 & 1235.31 & 883.48 & 1235.31 & 369.12 & 17 \\
\hline 25 & 43.75 & 919.6 & 963.35 & 1191.56 & 1235.31 & 61.04 & 23 \\
\hline 15 & 37.67 & 462.48 & 500.15 & 1184.24 & 1221.91 & 68.36 & 22 \\
\hline 21 & 85.97 & 797.51 & 883.48 & 797.51 & 883.48 & 455.09 & 16 \\
\hline 19 & 315.2 & 482.31 & 797.51 & 482.31 & 797.51 & 770.29 & 13 \\
\hline 24 & 82.46 & 837.14 & 919.6 & 1109.1 & 1191.56 & 143.5 & 20 \\
\hline 22 & 195.12 & 642.02 & 837.14 & 913.98 & 1109.1 & 338.62 & 18 \\
\hline 20 & 130.65 & 511.37 & 642.02 & 783.33 & 913.98 & 469.27 & 15 \\
\hline 16 & 19.83 & 462.48 & 482.31 & 462.48 & 482.31 & 790.12 & 12 \\
\hline 17 & 48.89 & 462.48 & 511.37 & 734.44 & 783.33 & 518.16 & 14 \\
\hline 6 & 41.6 & 108.57 & 150.17 & 1149.96 & 1191.56 & 102.64 & 21 \\
\hline 3 & 108.57 & 0 & 108.57 & 1041.39 & 1149.96 & 211.21 & 19 \\
\hline 13 & 25.49 & 436.99 & 462.48 & 436.99 & 462.48 & 815.61 & 11 \\
\hline 12 & 122.72 & 314.27 & 436.99 & 314.27 & 436.99 & 938.33 & 10 \\
\hline 11 & 12.02 & 302.25 & 314.27 & 302.25 & 314.27 & 950.35 & 9 \\
\hline 5 & 125.96 & 74.02 & 199.98 & 188.31 & 314.27 & 1064.29 & 6 \\
\hline 2 & 74.02 & 0 & 74.02 & 114.29 & 188.31 & 1138.31 & 3 \\
\hline 9 & 18.47 & 208.88 & 227.35 & 283.78 & 302.25 & 968.82 & 8 \\
\hline
\end{tabular}




\begin{tabular}{|c|r|r|r|r|r|r|r|}
\hline $\begin{array}{c}\text { Work } \\
\text { Element }\end{array}$ & \multicolumn{1}{c|}{$\begin{array}{c}\text { Standard } \\
\text { Time }\end{array}$} & ES & EF & LS & LF & ACTIM & $\begin{array}{c}\text { ACTIM } \\
\text { Rank }\end{array}$ \\
\hline 10 & 93.37 & 208.88 & 302.25 & 208.88 & 302.25 & 1043.72 & 7 \\
\hline 8 & 44.4 & 164.48 & 208.88 & 164.48 & 208.88 & 1088.12 & 5 \\
\hline 7 & 25.97 & 138.51 & 164.48 & 138.51 & 164.48 & 1114.09 & 4 \\
\hline 4 & 87.11 & 51.4 & 138.51 & 51.4 & 138.51 & 1201.2 & 2 \\
\hline 1 & 51.4 & 0 & 51.4 & 0 & 51.4 & 1252.6 & 1 \\
\hline
\end{tabular}

Table 4. Calculation of ES, EF, LS, dan LF

Table 5 shows the scheduling using ACTIM rule, where each of the work element only requires maximum one resource $(R \max =1)$ and number of resource being assigned for one unit PHB-TR 252 electrical circuit is two people $(\mathrm{n}(\mathrm{r})=2)$.

\begin{tabular}{|l|r|r|r|r|r|r|r|r|r|}
\hline & \multicolumn{1}{|c|}{1} & \multicolumn{1}{c|}{4} & \multicolumn{1}{c|}{$\mathbf{2}$} & \multicolumn{1}{c|}{$\mathbf{8}$} & \multicolumn{1}{c}{5} & 10 & 9 & 11 \\
\hline Duration (second) & 51.4 & 87.11 & 74.02 & 25.97 & 44.4 & 125.96 & 93.37 & 18.47 & 12.02 \\
\hline ACTIM & 1252.6 & 1201.2 & 1138.31 & 1114.09 & 1088.12 & 1064.29 & 1043.72 & 968.82 & 950.35 \\
\hline Scaled ACTIM & 100 & 95.8965 & 90.8758 & 88.9422 & 86.8689 & 84.9665 & 83.3243 & 77.3447 & 75.8702 \\
\hline Resource required & 1 & 1 & 1 & 1 & 1 & 1 & 1 & 1 & 1 \\
\hline TEARL & 0 & 51.4 & 0 & 138.51 & 164.48 & 74.02 & 208.88 & 208.88 & 302.25 \\
\hline TSCHED & 0 & 51.4 & 0 & 138.51 & 164.48 & 74.02 & 208.88 & 302.25 & 320.72 \\
\hline TFIN & 51.4 & 138.51 & 74.02 & 164.48 & 208.88 & 199.98 & 302.25 & 320.72 & 332.74 \\
\hline TNOW & 0 & 51.4 & 74.02 & 138.51 & 164.48 & 199.98 & 208.88 & 302.25 & 308.55 \\
\hline Resource available & - & - & - & - & - & - & - & - & - \\
\hline Activities allowed & $1,2,3$ & 4,3 & 5,3 & 7,3 & 8,3 & 3 & 10,9 & 9 & 6 \\
\hline Iteration number & 1 & 2 & 3 & 4 & 5 & 6 & 7 & 8 & 9 \\
\hline
\end{tabular}

\begin{tabular}{|c|c|c|c|c|c|c|c|}
\hline 12 & 13 & 16 & 19 & 17 & 20 & 21 & 23 \\
\hline 122.72 & 25.49 & 19.83 & 315.2 & 48.89 & 130.65 & 85.97 & 351.83 \\
\hline 938.33 & 815.61 & 790.12 & 770.29 & 518.16 & 469.27 & 455.09 & 369.12 \\
\hline 74.9106 & 65.1134 & 63.0784 & 61.49529 & 41.36675715 & 37.46368 & 36.33163 & 29.4683 \\
\hline 1 & 1 & 1 & 1 & 1 & 1 & 1 & 1 \\
\hline 314.27 & 436.99 & 462.48 & 482.31 & 462.48 & 511.37 & 797.51 & 883.48 \\
\hline 332.74 & 455.46 & 480.95 & 500.78 & 480.95 & 529.84 & 815.98 & 901.95 \\
\hline 455.46 & 480.95 & 500.78 & 815.98 & 529.84 & 660.49 & 901.95 & 1253.78 \\
\hline 320.72 & 332.74 & 350.15 & 455.56 & 480.95 & 500.78 & 529.84 & 660.49 \\
\hline- & - & r2 & $\mathrm{r} 1$ & - & - & - & - \\
\hline 11 & 12 & - & 13 & $16,17,15,14$ & $19,15,14$ & $20,15,14$ & $22,15,14$ \\
\hline 10 & 11 & 12 & 13 & 14 & 15 & 16 & 17 \\
\hline & & & Second & Percentage & & & \\
\hline & & idler r1 & 219.57 & 17.27 & & & \\
\hline & & idler r2 & 122.6 & 9.65 & & & \\
\hline
\end{tabular}




\begin{tabular}{|c|c|c|c|c|c|c|c|c|}
\hline 22 & 3 & 24 & 6 & 15 & 25 & 14 & 18 & 26 \\
\hline 195.12 & 108.57 & 82.46 & 41.6 & 37.67 & 43.75 & 26.81 & 13.4 & 17.29 \\
\hline 338.62 & 211.21 & 143.5 & 102.64 & 68.36 & 61.04 & 44.1 & 30.69 & 17.29 \\
\hline 27.03337 & 16.8617 & 11.4562 & 8.19416 & 5.45745 & 4.87306 & 3.52068 & 2.4501 & 1.38033 \\
\hline 1 & 1 & 1 & 1 & 1 & 1 & 1 & 1 & 1 \\
\hline 642.02 & 0 & 837.14 & 108.57 & 462.48 & 919.6 & 462.48 & 500.15 & 1235.31 \\
\hline 660.49 & 199.98 & 855.61 & 308.55 & 938.07 & 975.74 & 1019.49 & 1046.3 & 1253.78 \\
\hline 855.61 & 308.55 & 938.07 & 350.15 & 975.74 & 1019.49 & 1046.3 & 1059.7 & 1271.07 \\
\hline 815.98 & 855.61 & 901.95 & 938.07 & 975.74 & 1019.49 & 1046.3 & 1059.7 & 1253.78 \\
\hline- & - & - & - & - & - & - & r1 & r2 \\
\hline $21,15,14$ & $24,15,14$ & $23,15,14$ & $15,25,14$ & $25,14,18$ & 14,18 & 18 & 26 & - \\
\hline 18 & 19 & 20 & 21 & 22 & 23 & 24 & 25 & 26 \\
\hline
\end{tabular}

Table 5. ACTIM Scheduling, $\operatorname{Rmax}=1, \mathrm{n}(\mathrm{r})=2($ Scenario 1$)$

The scheduling table is then converted to the easy-to-interpret diagram, that is Gantt Chart (Figure 8). The time completion for whole activities are 1271.07 seconds, while idle rate for the resource 1 is $17.27 \%$ and resource 2 is $9.65 \%$

R2

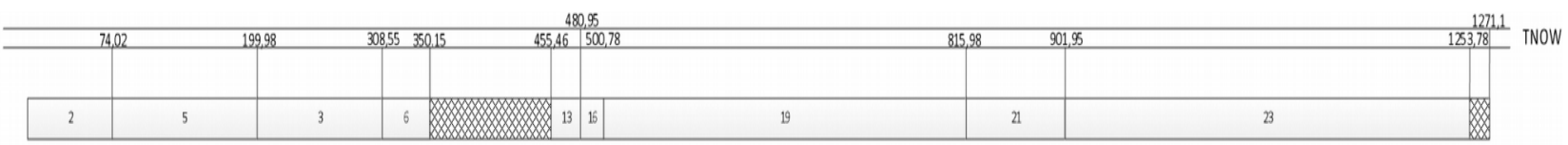

R1

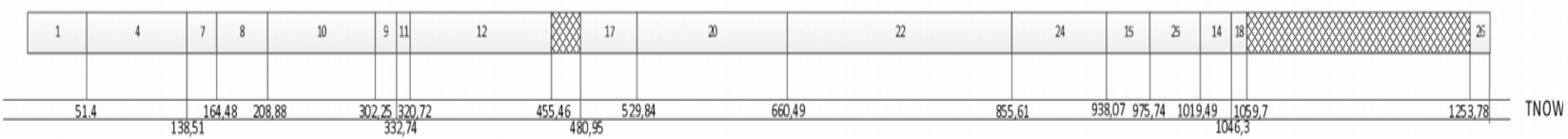

Figure 8. Gantt Chart for the ACTIM Scheduling (Scenario 1)

Moreover, for the Rmax $=1$, the attempt is made for the assignment of 3 resources or $n(r)=3$ to accomplish 1 unit electrical circuit. Table 6 shows the heuristic scheduling using ACTIM rule for $n(r)=3$ and follows by the Gantt Chart diagram to visualize the scheduling (Figure 9). The time completion for whole activities are 1252.6 seconds, while the idle rate for resource 1 is $27.5 \%$, resource 2 is $48.16 \%$, and resource 3 is $48.8 \%$. It indicates that when the number of resource assignment is increased, idle rate will raise and the completion time is reducing but not significant, that is only 18.47 seconds.

\begin{tabular}{|c|c|c|c|c|c|c|c|c|c|}
\hline & 1 & 4 & 2 & 7 & 8 & 5 & 10 & 9 & 11 \\
\hline Duration (second) & 51.4 & 87.11 & 74.02 & 25.97 & 44.4 & 125.96 & 93.37 & 18.47 & 12.02 \\
\hline ACTIM & 1281.66 & 1230.26 & 1167.37 & 1143.15 & 1117.18 & 1093.35 & 1072.78 & 997.88 & 979.41 \\
\hline Scaled ACTIM & 102.32 & 98.2165 & 93.1958 & 91.2622 & 89.1889 & 87.2864 & 85.6443 & 79.6647 & 78.1902 \\
\hline Resource required & 1 & 1 & 1 & 1 & 1 & 1 & 1 & 1 & 1 \\
\hline TEARL & 0 & 51.4 & 0 & 138.51 & 164.48 & 74.02 & 208.88 & 208.88 & 302.25 \\
\hline TSCHED & 0 & 51.4 & 0 & 138.51 & 164.48 & 74.02 & 208.88 & 208.88 & 302.25 \\
\hline TFIN & 51.4 & 138.51 & 74.02 & 164.48 & 208.88 & 199.98 & 302.25 & 227.35 & 314.27 \\
\hline TNOW & 0 & 51.4 & 74.02 & 108.57 & 138.51 & 150.17 & 164.48 & 198.88 & 208.88 \\
\hline Resource available & - & - & - & - & - & r3 & r1 & $\mathrm{r} 1, \mathrm{r} 3$ & r3 \\
\hline Activities allowed & $1,2,3$ & 4 & 5 & 6 & 7 & - & 8 & - & 9,10 \\
\hline Iteration number & 1 & 2 & 3 & 4 & 5 & 6 & 7 & 8 & 9 \\
\hline
\end{tabular}




\begin{tabular}{|c|c|c|c|c|c|c|c|}
\hline 12 & 13 & 16 & 19 & 17 & 20 & 21 & 23 \\
\hline 122.72 & 25.49 & 19.83 & 315.2 & 48.89 & 130.65 & 85.97 & 351.83 \\
\hline 967.39 & 844.67 & 819.18 & 799.36 & 547.22 & 498.33 & 484.15 & 398.18 \\
\hline 77.2306 & 67.4333 & 65.3984 & 63.815526 & 43.6867316 & 39.78365 & 38.6516 & 31.7883 \\
\hline 1 & 1 & 1 & 1 & 1 & 1 & 1 & 1 \\
\hline 314.27 & 436.99 & 462.48 & 482.31 & 462.48 & 511.37 & 797.51 & 883.48 \\
\hline 314.27 & 436.99 & 462.48 & 482.31 & 462.48 & 511.37 & 797.51 & 883.48 \\
\hline 436.99 & 462.48 & 482.31 & 797.51 & 511.37 & 642.02 & 883.48 & 1235.31 \\
\hline 227.35 & 302.25 & 314.27 & 436.99 & 462.28 & 482.31 & 500.15 & 511.37 \\
\hline $\mathrm{r} 2, \mathrm{r} 3$ & $\mathrm{r} 1, \mathrm{r} 2$ & $\mathrm{r} 1, \mathrm{r} 3$ & $\mathrm{r} 2, \mathrm{r} 3$ & - & - & - & - \\
\hline- & 11 & 12 & 13 & $16,17,15,14$ & 19,14 & 14,18 & 20,18 \\
\hline 10 & 11 & 12 & 13 & 14 & 15 & 16 & 17 \\
\hline & & & Second & Percentage & & & \\
\hline & & idler $\mathrm{r} 1$ & 344.43 & 27.50 & & & \\
\hline & & idler r2 & 603.27 & 48.16 & & & \\
\hline & & idler $r 3$ & 611.23 & 48.80 & & & \\
\hline
\end{tabular}

\begin{tabular}{|r|r|r|r|r|r|r|r|r|}
\hline \multicolumn{1}{|c|}{32} & \multicolumn{1}{c|}{24} & \multicolumn{1}{c|}{$\mathbf{6}$} & \multicolumn{1}{c|}{15} & \multicolumn{1}{c|}{25} & \multicolumn{1}{c|}{14} & \multicolumn{1}{c|}{18} & \multicolumn{1}{c|}{26} \\
\hline 195.12 & 108.57 & 82.46 & 41.6 & 37.67 & 43.75 & 2681 & 13.4 & 17.29 \\
\hline 367.68 & 240.27 & 172.56 & 131.7 & 97.42 & 90.1 & 73.16 & 59.75 & 46.35 \\
\hline 29.35335 & 19.1819 & 13.7761 & 10.5141 & 7.77742 & 7.19304 & 5.84065 & 4.77008 & 3.7003 \\
\hline 1 & 1 & 1 & 1 & 1 & 1 & 1 & 1 & 1 \\
\hline 642.02 & 0 & 837.14 & 108.57 & 462.48 & 919.6 & 462.48 & 500.15 & 1235.31 \\
\hline 642.02 & 0 & 837.14 & 108.57 & 462.48 & 919.6 & 500.15 & 526.96 & 1235.31 \\
\hline 837.14 & 108.57 & 919.6 & 150.17 & 500.15 & 963.35 & 526.96 & 540.36 & 1252.6 \\
\hline 526.96 & 540.36 & 642.02 & 797.51 & 837.14 & 883.48 & 919.6 & 963.35 & 1235.31 \\
\hline- & $\mathrm{r} 1$ & $\mathrm{r} 2$ & $\mathrm{r} 3$ & $\mathrm{r} 1$ & $\mathrm{r} 2$ & $\mathrm{r} 3$ & $\mathrm{r} 2, \mathrm{r} 3$ & $\mathrm{r} 1, \mathrm{r} 2$ \\
\hline 18 & - & 22 & 21 & 24 & 23 & 25 & - & 26 \\
\hline 18 & 19 & 20 & 21 & 22 & 23 & 24 & 25 & 26 \\
\hline
\end{tabular}

Table 6. ACTIM Scheduling, $R \max =1, \mathrm{n}(\mathrm{r})=3$ (Scenario 2$)$

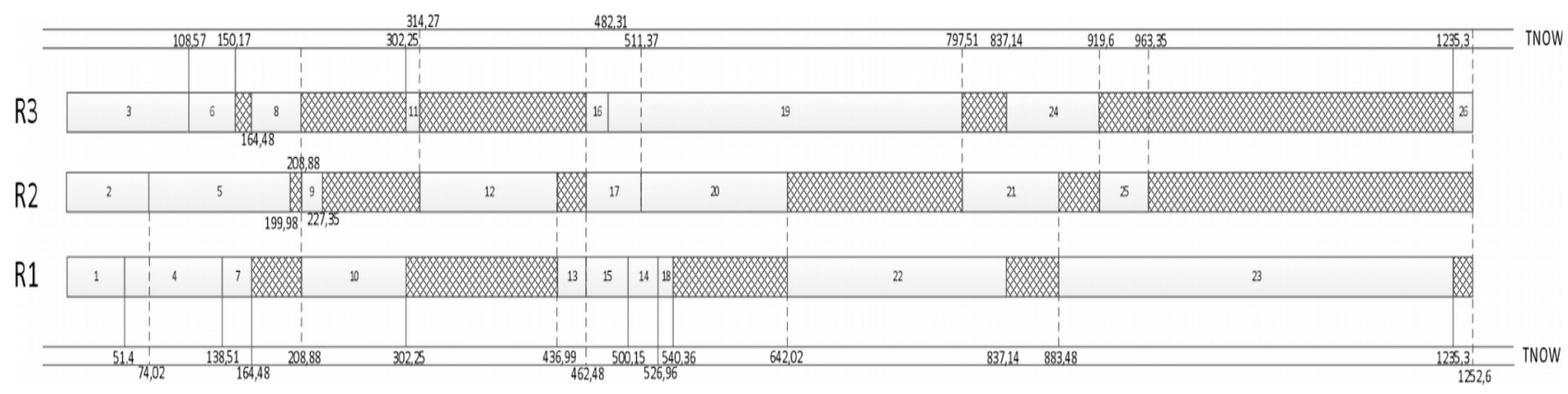

Figure 9. Gantt Chart for the ACTIM Scheduling (Scenario 2) 
Then, the other scenarios are formulated by making a list of the work element that enabling the accomplishment using 2 or 3 resources, so that the standard time assumed to be reduced linearly based on the number of resource being assigned. The list is made by conducting an interview to the Head of Assembly Department, regarding which of these work elements could be conducted by 2 or 3 people without interrupting the processing flow of the other work elements. The result is depicted by the following table.

\begin{tabular}{|c|c|c|c|c|}
\hline \multirow[b]{2}{*}{ No } & \multirow[b]{2}{*}{ Work Element } & \multicolumn{2}{|c|}{ Possibility being conducted by } & \multirow[b]{2}{*}{ Information } \\
\hline & & 2 people & 3 people & \\
\hline 1 & Clean up the paper tape sticked to the bolt & Yes & Yes & Per bolt \\
\hline 2 & Assemble the MCCB into the MCCB base & Yes* & No & \\
\hline 3 & Insert busbar N M10 bolt & Yes* & No & \\
\hline 4 & Assemble the R, S, T, N, recolt & Yes & Yes & Per bolt \\
\hline 5 & Install the connector busbar and busbar tongue into the MCCB & Yes* & No & \\
\hline $5-1$ & Busbar tongue installment & & & \\
\hline $5-2$ & Connector busbar installment & & & \\
\hline 6 & Insert the busbae $\mathrm{N}$ & Yes* & No & \\
\hline 7 & Measure the hole position of busbar R, S & No & No & Per busbar \\
\hline 8 & Drill the busbar R, S & Yes* & No & Per busbar \\
\hline 9 & Assemble the left side bolt of busbar R, S, T & No & No & \\
\hline 10 & Assemble the CT-R, CT-S, and CT-T & Yes* & No & \\
\hline $10-1$ & Assemble the CT-R and CT-S (including wrap detachment) & & & \\
\hline $10-2$ & Open the CT-T wrap & & & \\
\hline $10-3$ & Assemble the CT-T & & & \\
\hline 11 & Insert the right side bolt of busbar $\mathrm{R}, \mathrm{S}, \mathrm{T}$ & No & No & \\
\hline 12 & Install the MCCB into phase busbar & Yes* & No & \\
\hline 13 & Insert the mould to straighten the busbar & No & No & \\
\hline 14 & Fasten the M10 connector bolt & No & No & \\
\hline 15 & Fasten the MCCB L8 bolt & No & No & \\
\hline 16 & Fasten the $\mathrm{R}, \mathrm{S}, \mathrm{T}$ recolit bolt & No & No & \\
\hline 17 & Insert the foofing bolt to the MCCB base & No & No & \\
\hline 18 & Insert the MCCB valve & No & No & \\
\hline 19 & Assemble the fuse rail & Yes & Yes & \\
\hline $19-1$ & Insert the bolt & & & \\
\hline $19-2$ & Assemble the fuse rail & & & \\
\hline $19-3$ & Fasten the bolt manually & & & \\
\hline 20 & Drilling the busbar tongue recolit hole & No & No & \\
\hline 21 & Fasten the fuse rail bolt & No & No & \\
\hline 22 & Assemble busbar tongue recolit & Yes* & No & \\
\hline 23 & Assemble the CT fastener & Yes & No & \\
\hline 24 & Insert the baut busbar tongue M10 bolt & Yes & No & \\
\hline 25 & Fasten the busbar $\mathrm{N}$ and busbar tongue bolt & No & No & \\
\hline 26 & Fasten the overall bolt through backside & Yes* & No & \\
\hline
\end{tabular}

Table 7. Check List of the Work Element that Enabling the Accomplishment Using 2 or 3 Resources 
On the Table 7, if the yes appears with the sign of $(*)$, then the work element is enabled to be conducted by 2 or 3 people, but if that is happened, the reduction of the time completion isn't appeared to be linear, because the characteristic of the task is not made from the similiar subelement. Also, the assistance from the additional worker wouldn't give a significant effect. Therefore, for the answer yes using sign $(*)$, is assumed to be not included in the work element list that could be conducted by additional worker.

The precedence diagram along with its critical path on below, shows the change in the standard time for several work elements that is given the additional worker.

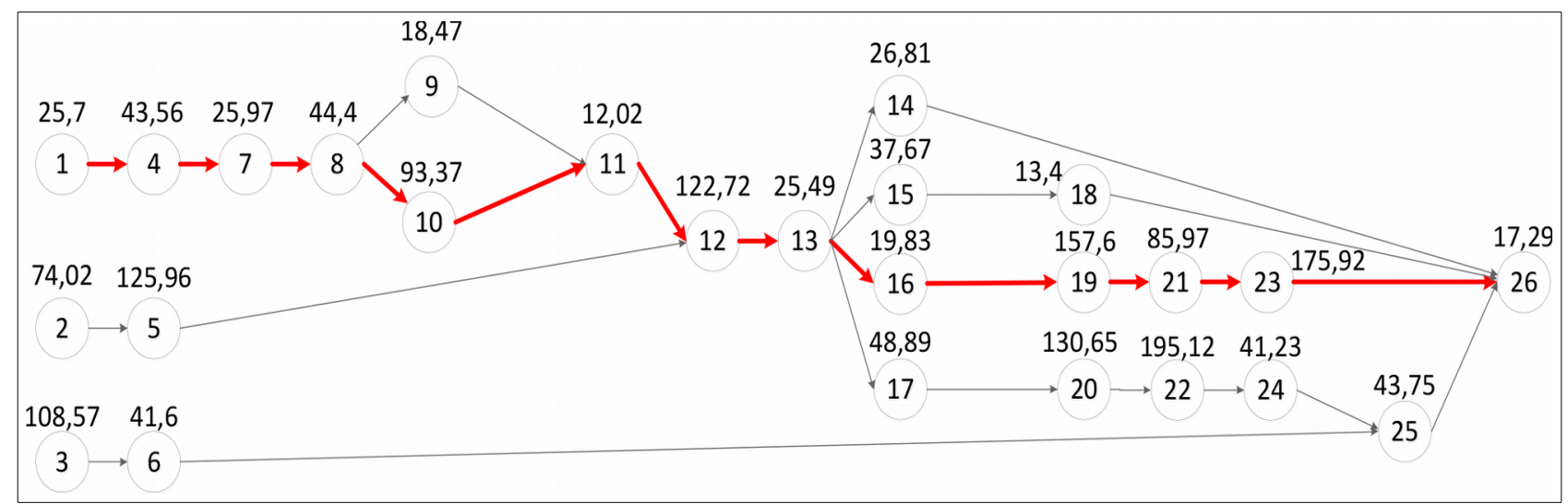

Figure 10. The AON for the PHB-TR 252 Assembly Process Using One Additional

Worker for Particular Work Element $(\operatorname{Rmax}=2)$

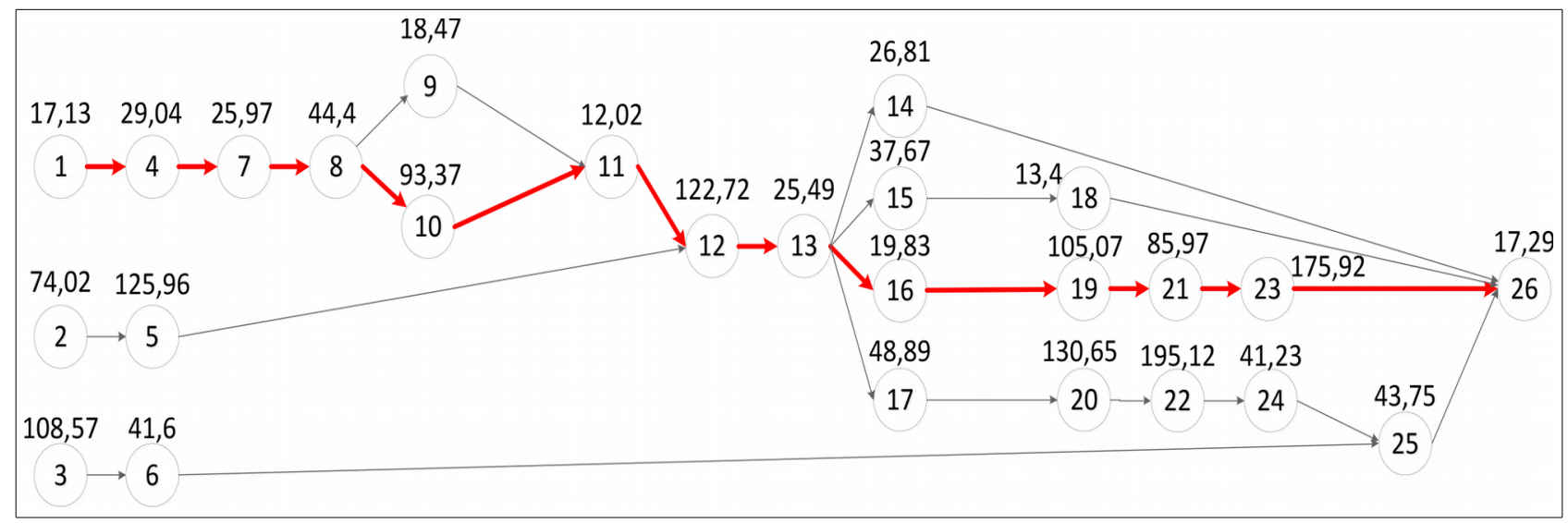

Figure 11. The AON for the PHB-TR 252 Assembly Process Using Two Additional Worker for Particular Work Element $(\operatorname{Rmax}=3)$

Furthermore, the calculation result of ES, LS, EF, LF, ACTIM, ACTRES, and TIMRES after being adjusted with one additional worker for several work elements $(\operatorname{Rmax}=2)$, are provided on the table below. 


\begin{tabular}{|c|c|c|c|c|c|c|c|c|c|c|c|c|}
\hline $\begin{array}{c}\text { Work } \\
\text { Element }\end{array}$ & $\begin{array}{l}\text { Resource } \\
\text { Max }=2\end{array}$ & $\begin{array}{l}\text { Standard } \\
\text { Time with } \\
\text { Adjusment } \\
\text { of the } \\
\text { Additional } \\
\text { Worker }\end{array}$ & ES & $\mathbf{E F}$ & $\mathbf{L S}$ & $\mathbf{L F}$ & ACTIM & $\left|\begin{array}{c}\text { ACTIM } \\
\text { Rank }\end{array}\right|$ & ACTRES & $\begin{array}{c}\text { ACTRES } \\
\text { Rank }\end{array}$ & TIMERES & $\begin{array}{c}\text { TIMERES } \\
\text { Rank }\end{array}$ \\
\hline 26 & 1 & 17.29 & 852.87 & 870.16 & 852.87 & 870.16 & 17.29 & 26 & 17.29 & 26 & 17.29 & 26 \\
\hline 14 & 1 & 26.81 & 393.23 & 420.04 & 826.06 & 852.87 & 44.10 & 24 & 44.1 & 24 & 44.10 & 24 \\
\hline 18 & 1 & 13.40 & 430.90 & 444.30 & 839.47 & 852.87 & 30.69 & 25 & 30.69 & 25 & 30.69 & 25 \\
\hline 23 & 2 & 175.92 & 656.63 & 832.55 & 676.95 & 852.87 & 193.21 & 19 & 386.42 & 16 & 289.82 & 17 \\
\hline 25 & 1 & 43.75 & 809.12 & 852.87 & 809.12 & 852.87 & 61.04 & 23 & 61.04 & 23 & 61.04 & 23 \\
\hline 15 & 1 & 37.67 & 393.23 & 430.90 & 801.80 & 839.47 & 68.36 & 22 & 68.36 & 22 & 68.36 & 22 \\
\hline 21 & 1 & 85.97 & 570.66 & 656.63 & 590.98 & 676.95 & 279.18 & 17 & 279.18 & 18 & 279.18 & 18 \\
\hline 19 & 2 & 157.60 & 413.06 & 570.66 & 433.38 & 590.98 & 436.78 & 14 & 873.56 & 3 & 655.17 & 9 \\
\hline 24 & 2 & 41.23 & 767.89 & 809.12 & 767.89 & 809.12 & 102.27 & 21 & 204.54 & 20 & 153.41 & 20 \\
\hline 22 & 1 & 195.12 & 572.77 & 767.89 & 572.77 & 767.89 & 297.39 & 16 & 297.39 & 17 & 297.39 & 16 \\
\hline 20 & 1 & 130.65 & 442.12 & 572.77 & 442.12 & 572.77 & 428.04 & 15 & 428.04 & 15 & 428.04 & 15 \\
\hline 16 & 1 & 19.83 & 393.23 & 413.06 & 413.55 & 433.38 & 456.61 & 13 & 456.61 & 14 & 456.61 & 14 \\
\hline 17 & 1 & 48.89 & 393.23 & 442.12 & 393.23 & 442.12 & 476.93 & 12 & 476.93 & 13 & 476.93 & 13 \\
\hline 6 & 1 & 41.6 & 108.57 & 150.17 & 767.52 & 809.12 & 102.64 & 20 & 102.64 & 21 & 102.64 & 21 \\
\hline 3 & 1 & 108.57 & 0 & 108.57 & 658.95 & 767.52 & 211.21 & 18 & 211.21 & 19 & 211.21 & 19 \\
\hline 13 & 1 & 25.49 & 367.74 & 393.23 & 367.74 & 393.23 & 502.42 & 11 & 502.42 & 12 & 502.42 & 12 \\
\hline 12 & 1 & 122.72 & 245.02 & 367.74 & 245.02 & 367.74 & 625.14 & 10 & 625.14 & 11 & 625.14 & 11 \\
\hline 11 & 1 & 12.02 & 233.00 & 245.02 & 233.00 & 245.02 & 637.16 & 9 & 637.16 & 10 & 637.16 & 10 \\
\hline 5 & 1 & 125.96 & 74.02 & 199.98 & 119.06 & 245.02 & 751.10 & 6 & 751.1 & 7 & 751.10 & 6 \\
\hline 2 & 1 & 74.02 & 0 & 74.02 & 45.04 & 119.06 & 825.12 & 3 & 825.12 & 4 & 825.12 & 3 \\
\hline 9 & 1 & 18.47 & 139.63 & 158.10 & 214.53 & 233.00 & 655.63 & 8 & 655.63 & 9 & 655.63 & 8 \\
\hline 10 & 1 & 93.37 & 139.63 & 233.00 & 139.63 & 233.00 & 730.53 & 7 & 730.53 & 8 & 730.53 & 7 \\
\hline 8 & 1 & 44.4 & 95.23 & 139.63 & 95.23 & 139.63 & 774.93 & 5 & 774.93 & 6 & 774.93 & 5 \\
\hline 7 & 1 & 25.97 & 69.26 & 95.23 & 69.26 & 95.23 & 800.90 & 4 & 800.9 & 5 & 800.90 & 4 \\
\hline 4 & 2 & 43.56 & 25.70 & 69.26 & 25.70 & 69.26 & 844.46 & 2 & 1688.92 & 2 & 1266.69 & 2 \\
\hline 1 & 2 & 25.70 & 0 & 25.70 & 0.00 & 25.70 & 870.16 & 1 & 1740.32 & 1 & 1305.24 & 1 \\
\hline
\end{tabular}

Table 8. Calculation of ES, LS, EF, LF, ACTIM, ACTRES, and TIMRES for Rmax $=2$

While Table 9 shows the calculation result of ES, LS, EF, LF, ACTIM, ACTRES, and TIMRES after being adjusted with two additional workers for several work elements $(\mathrm{R} \max =3)$. 


\begin{tabular}{|c|c|c|c|c|c|c|c|c|c|c|c|c|}
\hline $\begin{array}{l}\text { Work } \\
\text { Element }\end{array}$ & $\begin{array}{l}\text { Resource } \\
\operatorname{Max}=3\end{array}$ & $\begin{array}{l}\text { Standard } \\
\text { Time with } \\
\text { Adjusment } \\
\text { of the } \\
\text { Additional } \\
\text { Worker }\end{array}$ & ES & EF & LS & $\mathbf{L F}$ & ACTIM & $\begin{array}{c}\text { ACTIM } \\
\text { Rank }\end{array}$ & ACTRES & $\begin{array}{l}\text { ACTRES } \\
\text { Rank }\end{array}$ & TIMERES & $\begin{array}{c}\text { TIMERES } \\
\text { Rank }\end{array}$ \\
\hline 26 & 1 & 17.29 & 829.78 & 847.07 & 829.78 & 847.07 & 17.29 & 26 & 17.29 & 26 & 17.29 & 26 \\
\hline 14 & 1 & 26.81 & 370.14 & 396.95 & 802.97 & 829.78 & 44.10 & 24 & 44.1 & 24 & 44.10 & 24 \\
\hline 18 & 1 & 13.40 & 407.81 & 421.21 & 816.38 & 829.78 & 30.69 & 25 & 30.69 & 25 & 30.69 & 25 \\
\hline 23 & 2 & 175.92 & 581.01 & 756.93 & 653.86 & 829.78 & 193.21 & 19 & 386.42 & 16 & 289.82 & 17 \\
\hline 25 & 1 & 43.75 & 786.03 & 829.78 & 786.03 & 829.78 & 61.04 & 23 & 61.04 & 23 & 61.04 & 23 \\
\hline 15 & 1 & 37.67 & 370.14 & 407.81 & 778.71 & 816.38 & 68.36 & 22 & 68.36 & 22 & 68.36 & 22 \\
\hline 21 & 1 & 85.97 & 495.04 & 581.01 & 567.89 & 653.86 & 279.18 & 17 & 279.18 & 18 & 279.18 & 18 \\
\hline 19 & 3 & 105.07 & 389.97 & 495.04 & 462.82 & 567.89 & 384.25 & 15 & 1152.75 & 3 & 768.50 & 6 \\
\hline 24 & 2 & 41.23 & 744.80 & 786.03 & 744.80 & 786.03 & 102.27 & 21 & 204.54 & 20 & 153.41 & 20 \\
\hline 22 & 1 & 195.12 & 549.68 & 744.80 & 549.68 & 744.80 & 297.39 & 16 & 297.39 & 17 & 297.39 & 16 \\
\hline 20 & 1 & 130.65 & 419.03 & 549.68 & 419.03 & 549.68 & 428.04 & 13 & 428.04 & 14 & 428.04 & 14 \\
\hline 16 & 1 & 19.83 & 370.14 & 389.97 & 442.99 & 462.82 & 404.08 & 14 & 404.08 & 15 & 404.08 & 15 \\
\hline 17 & 1 & 48.89 & 370.14 & 419.03 & 370.14 & 419.03 & 476.93 & 12 & 476.93 & 13 & 476.93 & 13 \\
\hline 6 & 1 & 41.6 & 108.57 & 150.17 & 744.43 & 786.03 & 102.64 & 20 & 102.64 & 21 & 102.64 & 21 \\
\hline 3 & 1 & 108.57 & 0 & 108.57 & 635.86 & 744.43 & 211.21 & 18 & 211.21 & 19 & 211.21 & 19 \\
\hline 13 & 1 & 25.49 & 344.65 & 370.14 & 344.65 & 370.14 & 502.42 & 11 & 502.42 & 12 & 502.42 & 12 \\
\hline 12 & 1 & 122.72 & 221.93 & 344.65 & 221.93 & 344.65 & 625.14 & 10 & 625.14 & 11 & 625.14 & 11 \\
\hline 11 & 1 & 12.02 & 209.91 & 221.93 & 209.91 & 221.93 & 637.16 & 9 & 637.16 & 10 & 637.16 & 10 \\
\hline 5 & 1 & 125.96 & 74.02 & 199.98 & 95.97 & 221.93 & 751.10 & 6 & 751.1 & 7 & 751.10 & 7 \\
\hline 2 & 1 & 74.02 & 0 & 74.02 & 21.95 & 95.97 & 825.12 & 3 & 825.12 & 4 & 825.12 & 3 \\
\hline 9 & 1 & 18.47 & 116.54 & 135.01 & 191.44 & 209.91 & 655.63 & 8 & 655.63 & 9 & 655.63 & 9 \\
\hline 10 & 1 & 93.37 & 116.54 & 209.91 & 116.54 & 209.91 & 730.53 & 7 & 730.53 & 8 & 730.53 & 8 \\
\hline 8 & 1 & 44.4 & 72.14 & 116.54 & 72.14 & 116.54 & 774.93 & 5 & 774.93 & 6 & 774.93 & 5 \\
\hline 7 & 1 & 25.97 & 46.17 & 72.14 & 46.17 & 72.14 & 800.90 & 4 & 800.9 & 5 & 800.90 & 4 \\
\hline 4 & 3 & 29.04 & 17.13 & 46.17 & 17.13 & 46.17 & 829.94 & 2 & 2489.82 & 2 & 1659.88 & 2 \\
\hline 1 & 3 & 17.13 & 0 & 17.13 & 0.00 & 17.13 & 847.07 & 1 & 2541.21 & 1 & 1694.14 & 1 \\
\hline
\end{tabular}

Table 9. Calculation of ES, LS, EF, LF, ACTIM, ACTRES, and TIMRES for Rmax $=3$

When there is a difference on the resource requirement between the work elements, the ACTRES and TIMRES rule could be applied as the comparison, because the ACTRES and TIMRES value consider the number of resource requirement on each of the work element. The scheduling using ACTIM, ACTRES, and TIMRES respectively shown by the following tables. 


\begin{tabular}{|c|c|c|c|c|c|c|c|c|c|}
\hline & 1 & 4 & 2 & 7 & 8 & 5 & 10 & 9 & 11 \\
\hline Duration (second) & 25.70 & 43.56 & 74.02 & 25.97 & 44.4 & 125.96 & 93.37 & 18.47 & 12.02 \\
\hline ACTIM & 870.16 & 844.46 & 825.12 & 800.90 & 774.93 & 751.10 & 730.53 & $65 . .63$ & 637.16 \\
\hline Scaled ACTIM & 100 & 97.0465 & 94.8239 & 92.0405 & 89.056 & 86.3175 & 83.9535 & 75.3459 & 73.2233 \\
\hline Resource required & 2 & 2 & 1 & 1 & 1 & 1 & 1 & 1 & 1 \\
\hline TEARL & 0 & 25.70 & 0 & 69.26 & 95.23 & 74.02 & 13963 & 139.63 & 302.25 \\
\hline TSCHED & 0 & 25.70 & 69.26 & 95.23 & 74.02 & 139.63 & 139.63 & 233 & 251.47 \\
\hline TFIN & 25.7 & 69.26 & 143.28 & 95.23 & 139.63 & 269.24 & 233 & 251.47 & 263.49 \\
\hline TNOW & 0 & 25.7 & 69.26 & 95.23 & 139.63 & 143.28 & 23333 & 251.47 & 263.49 \\
\hline Resource available & - & - & - & - & - & - & - & - & - \\
\hline Activities allowed & $1,2,3$ & $4,2,3$ & $2,7,3$ & 8,3 & $10,9,3$ & $5,9,3$ & 9,3 & 11,3 & 3 \\
\hline Iteration number & 1 & 2 & 3 & 4 & 5 & 6 & 7 & 8 & 9 \\
\hline
\end{tabular}

\begin{tabular}{|r|r|r|r|r|r|r|r|}
\hline 12 & 13 & 17 & 16 & 19 & \multicolumn{1}{c|}{20} & \multicolumn{1}{c|}{22} & \multicolumn{1}{c|}{21} \\
\hline 122.72 & 25.49 & 48.89 & 19.83 & 157.60 & 130.65 & 195.12 & 85.97 \\
\hline 625.14 & 502.42 & 476.93 & 456.61 & 436.78 & 428.04 & 297.39 & 279.18 \\
\hline 71.842 & 57.7388 & 54.8095 & 52.474258 & 50.19536637 & 49.191 & 34.1765 & 32.0838 \\
\hline 1 & 1 & 1 & 1 & 2 & 1 & 1 & 1 \\
\hline 314.27 & 436.99 & 462.48 & 482.31 & 462.48 & 511.37 & 797.51 & 883.48 \\
\hline 263.49 & 391.96 & 417.45 & 466.34 & 437.28 & 754.59 & 596.99 & 949.71 \\
\hline 391.96 & 417.45 & 466.34 & 437.28 & 754.59 & 569.99 & 949.71 & 840.56 \\
\hline 269.24 & 372.06 & 391.96 & 413.66 & 417.45 & 437.28 & 466.34 & 474.95 \\
\hline- & - & - & $\mathrm{r} 2$ & - & - & - & - \\
\hline 12 & 6 & 13 & - & $17,16,15,14$ & $19,15,14$ & $19,20,14$ & $19,14,18$ \\
\hline 10 & 11 & 12 & 13 & 14 & 15 & 16 & 17 \\
\hline
\end{tabular}

Second Percentage

\begin{tabular}{|l|l|r|}
\hline idler $\mathbf{r 1}$ & 125.58 & 10.23 \\
\hline idler $\mathbf{r}$ & 130.23 & 10.61 \\
\hline
\end{tabular}

\begin{tabular}{|r|r|r|r|r|r|r|r|r|}
\hline \multicolumn{1}{|c|}{$\mathbf{3}$} & \multicolumn{1}{c|}{$\mathbf{2 3}$} & \multicolumn{1}{c|}{$\mathbf{2 4}$} & \multicolumn{1}{c|}{15} & \multicolumn{1}{c|}{25} & \multicolumn{1}{c|}{14} & \multicolumn{1}{c|}{18} & \multicolumn{1}{c|}{26} \\
\hline 108.57 & 1751.92 & 41.6 & 41.23 & 37.67 & 43.75 & 26.81 & 13.40 & 17.29 \\
\hline 211.21 & 193.21 & 102.64 & 102.27 & 68.36 & 61.04 & 44.10 & 30.69 & 17.29 \\
\hline 24.2725 & 22.204 & 11.7955 & 11.753 & 7.85603 & 7.0148 & 5.06803 & 3.52694 & 1.98699 \\
\hline 1 & 2 & 1 & 2 & 1 & 1 & 1 & 1 & 1 \\
\hline 0 & 656.63 & 108.57 & 767.89 & 393.23 & 809.12 & 393.23 & 430.90 & 852.87 \\
\hline 263.49 & 949.71 & 372.06 & 1125.63 & 437.282 & 1166.86 & 474.95 & 501.76 & 1210.61 \\
\hline 372.06 & 1125.63 & 413.66 & 1166.86 & 474.95 & 1210.61 & 501.76 & 515.16 & 1227.9 \\
\hline 501.76 & 515.16 & 596.99 & 754.59 & 840.56 & 949.71 & 1125.63 & 1166.86 & 1210.61 \\
\hline- & $\mathrm{r} 1$ & - & - & $\mathrm{r} 2$ & - & - & $\mathrm{r} 1$ & $\mathrm{r} 2$ \\
\hline 19,18 & 19 & 19,22 & 22,21 & 23 & 23,24 & 24 & 25 & 26 \\
\hline 18 & 19 & 20 & 21 & 22 & 23 & 24 & 25 & 26 \\
\hline
\end{tabular}

Table 10. ACTIM Scheduling, $R \max =2, \mathrm{n}(\mathrm{r})=2$ (Scenario 3) 


\begin{tabular}{|c|c|c|c|c|c|c|c|c|c|}
\hline & 1 & 4 & 2 & 7 & 8 & 5 & 10 & 9 & 11 \\
\hline Duration (second) & 25.70 & 43.56 & 74.02 & 25.97 & 44.4. & 125.96 & 93.37 & 18.47 & 12.02 \\
\hline ACTIM & 870.16 & 844.46 & 825.12 & 800.90 & 774.93 & 751.10 & 730.53 & $655 . .63$ & 637.16 \\
\hline Scaled ACTIM & 100 & 97.0465 & 94.8239 & 92.0405 & 89.056 & 86.3175 & 83.9535 & 75.3459 & 73.2233 \\
\hline Resource required & 2 & 2 & 1 & 1 & 1 & 1 & 1 & 1 & 1 \\
\hline TEARL & 0 & 25.70 & 0 & 69.26 & 95.23 & 74.02 & 139.63 & 139.63 & 233.00 \\
\hline TSCHED & 0 & 25.7 & 0 & 69.26 & 95.23 & 74.02 & 139.63 & 177.83 & 233 \\
\hline TFIN & 25.7 & 69.26 & 74.02 & 95.23 & 139.63 & 199.98 & 233 & 196.3 & 245.02 \\
\hline TNOW & 0 & 25.7 & 69.26 & 74.02 & 95.23 & 139.63 & 177.83 & 196.3 & 199.98 \\
\hline Resource available & - & - & - & - & - & - & - & - & $\mathrm{r} 3$ \\
\hline Activities allowed & $1.2,3$ & 4,3 & 7,3 & 5 & 8 & 10,9 & 9,6 & 6 & - \\
\hline Iteration number & 1 & 2 & 3 & 4 & 5 & 6 & 7 & 8 & 9 \\
\hline
\end{tabular}

\begin{tabular}{|r|r|r|r|r|r|r|r|}
\hline 12 & \multicolumn{1}{|c|}{13} & \multicolumn{1}{c|}{17} & \multicolumn{1}{c|}{16} & \multicolumn{1}{c|}{19} & \multicolumn{1}{c|}{20} & \multicolumn{1}{c|}{22} & \multicolumn{1}{c|}{21} \\
\hline 122.72 & 25.49 & 48.89 & 19.83 & 157.60 & 130.65 & 195.12 & 85.97 \\
\hline 625.14 & 502.42 & 476.93 & 456.61 & 436.78 & 428.04 & 297.39 & 279.18 \\
\hline 71.842 & 57.7388 & 54.8095 & 52.474258 & 50.19536637 & 49.191 & 34.1765 & 32.0838 \\
\hline 1 & 1 & 1 & 1 & 2 & 1 & 1 & 1 \\
\hline 245.02 & 367.74 & 393.23 & 393.23 & 413.06 & 442.12 & 572.77 & 570.66 \\
\hline 245.02 & 367.74 & 393.23 & 393.23 & 442.12 & 444.3 & 574.95 & 599.72 \\
\hline 367.74 & 393.23 & 442.12 & 413.06 & 599.72 & 574.95 & 770.07 & 685.69 \\
\hline 233 & 237.9 & 245.02 & 367.74 & 393.23 & 413.06 & 430.9 & 439.87 \\
\hline $\mathrm{r} 1$ & $\mathrm{r} 1, \mathrm{r} 2$ & $\mathrm{r} 1, \mathrm{r} 2$ & $\mathrm{r} 1, \mathrm{r} 3$ & - & - & - & $\mathrm{r} 1$ \\
\hline 11 & - & 12 & 13 & $17,16,15,14$ & 19,14 & 19,18 & 19 \\
\hline 10 & 11 & 12 & 13 & 14 & 15 & 16 & 17 \\
\hline
\end{tabular}

\begin{tabular}{|l|r|r|} 
& \multicolumn{1}{|c|}{ Second } & \multicolumn{1}{|c|}{ Percentage } \\
\hline idler $\mathbf{r} 1$ & 221 & 22.93 \\
\hline idler $\mathbf{r} 2$ & 265.13 & 27.51 \\
\hline
\end{tabular}

\begin{tabular}{|r|r|r|r|r|r|r|r|r|}
\hline \multicolumn{1}{|c|}{$\mathbf{3}$} & \multicolumn{1}{c|}{$\mathbf{2 3}$} & \multicolumn{1}{c|}{$\mathbf{2 4}$} & \multicolumn{1}{c|}{15} & \multicolumn{1}{c|}{25} & \multicolumn{1}{c|}{14} & \multicolumn{1}{c|}{18} & \multicolumn{1}{c|}{26} \\
\hline 108.57 & 1751.92 & 41.6 & 41.23 & 37.67 & 43.75 & 26.81 & 13.40 & 17.29 \\
\hline 211.21 & 193.21 & 102.64 & 102.27 & 68.36 & 61.04 & 44.10 & 30.69 & 17.29 \\
\hline 24.2725 & 22.204 & 11.7955 & 11.753 & 7.85603 & 7.0148 & 5.06803 & 3.52694 & 1.98699 \\
\hline 1 & 2 & 1 & 2 & 1 & 1 & 1 & 1 & 1 \\
\hline 0 & 656.63 & 108.57 & 767.89 & 393.23 & 809.12 & 393.23 & 430.90 & 852.87 \\
\hline 69.26 & 685.69 & 196.3 & 861.61 & 393.23 & 902.84 & 413.06 & 430.9 & 946.59 \\
\hline 177.83 & 861.61 & 237.9 & 902.84 & 430.9 & 946.59 & 439.87 & 444.3 & 963.88 \\
\hline 442.12 & 444.3 & 574.95 & 599.72 & 685.69 & 770.07 & 861.61 & 902.84 & 946.59 \\
\hline- & - & - & $\mathrm{r} 3$ & - & $\mathrm{r} 2$ & $\mathrm{r} 1$ & $\mathrm{r} 2, \mathrm{r} 3$ & $\mathrm{r} 1, \mathrm{r} 3$ \\
\hline 19,20 & 20 & 22 & 21 & 23 & 24 & 24 & 25 & 26 \\
\hline 18 & 19 & 20 & 21 & 22 & 23 & 24 & 25 & 26 \\
\hline
\end{tabular}

Table 11. ACTIM Scheduling, $\operatorname{Rmax}=2, \mathrm{n}(\mathrm{r})=3$ (Scenario 4) 


\begin{tabular}{|c|c|c|c|c|c|c|c|c|c|}
\hline & 1 & 4 & 19 & 2 & 7 & 8 & 5 & 10 & 9 \\
\hline Duration (second) & 25.70 & 43.56 & 157.60 & 74.02 & 25.97 & 44.4 & 125.96 & 93.37 & 18.47 \\
\hline ACTIM & 1740.32 & 1688.92 & 873.56 & 852.12 & 800.9 & 774.93 & 751.1 & 730.53 & 655.63 \\
\hline Scaled ACTIM & 100 & 97.0465 & 50.1954 & 47.412 & 46.0203 & 44.528 & 43.1587 & 41.9768 & 37.673 \\
\hline Resource required & 2 & 2 & 2 & 1 & 1 & 1 & 1 & 1 & 1 \\
\hline TEARL & 0 & 25.70 & 413.60 & 0 & 69.26 & 95.23 & 74.02 & 139.63 & 139.63 \\
\hline TSCHED & 0 & 25.7 & 596.99 & 69.26 & 69.26 & 95.23 & 143.28 & 139.63 & 233 \\
\hline TFIN & 25.7 & 69.26 & 754.59 & 143.28 & 95.23 & 139.63 & 269.24 & 233 & 251.47 \\
\hline TNOW & 0 & 25.7 & 69.26 & 95.23 & 139.63 & 143.28 & 233 & 251.47 & 263.49 \\
\hline Resource available & - & - & - & - & - & - & - & - & - \\
\hline Activities allowed & $1,2,3$ & $4,2,3$ & $2,7,3$ & 8,3 & $10,9,3$ & $5,9,3$ & 9,3 & 11,3 & 3 \\
\hline Iteration number & 1 & 2 & 3 & 4 & 5 & 6 & 7 & 8 & 9 \\
\hline
\end{tabular}

\begin{tabular}{|r|r|r|r|r|r|r|r|}
\hline 11 & 12 & \multicolumn{1}{c|}{13} & \multicolumn{1}{c|}{17} & \multicolumn{1}{c|}{16} & \multicolumn{1}{c|}{20} & \multicolumn{1}{c|}{23} & \multicolumn{1}{c|}{22} \\
\hline 12.02 & 122.72 & 25.49 & 48.89 & 19.83 & 130.65 & 175.92 & 195.12 \\
\hline 637.16 & 625.14 & 502.42 & 476.93 & 456.61 & 428.04 & 386.42 & 297.39 \\
\hline 36.6117 & 35.921 & 28.8694 & 27.40473 & 26.2371288 & 24.5954767 & 22.204 & 17.0882 \\
\hline 1 & 1 & 1 & 1 & 1 & 1 & 2 & 1 \\
\hline 233.00 & 245.02 & 367.74 & 393.23 & 393.23 & 442.12 & 656.63 & 572.77 \\
\hline 251.47 & 269.24 & 391.96 & 417.45 & 417.45 & 466.34 & 949.71 & 754.59 \\
\hline 263.49 & 391.96 & 417.45 & 466.34 & 437.28 & 596.99 & 1125.63 & 949.71 \\
\hline 269.24 & 372.06 & 391.96 & 413.66 & 417.45 & 437.28 & 466.34 & 474.95 \\
\hline- & - & - & $\mathrm{r} 2$ & - & - & - & - \\
\hline 12 & 6 & 13 & - & $17,16,15,14$ & $19,15,14$ & $19,20,14$ & $19,14,18$ \\
\hline 10 & 11 & 12 & 13 & 14 & 15 & 16 & 17 \\
\hline
\end{tabular}

Second Percentage

\begin{tabular}{|l|l|l|}
\hline idler $\mathbf{r} 1$ & 125.58 & 10.23 \\
\hline idler $\mathbf{r}$ & 130.23 & 10.61 \\
\hline
\end{tabular}

\begin{tabular}{|c|c|c|c|c|c|c|c|c|}
\hline 21 & 3 & 24 & 6 & 15 & 25 & 14 & 18 & 26 \\
\hline 85.97 & 108.57 & 41.23 & 41.6 & 37.67 & 43.75 & 26.81 & 13.40 & 17.29 \\
\hline 279.18 & 211.21 & 204.54 & 102.64 & 68.36 & 61.04 & 44.10 & 30.69 & 17.29 \\
\hline 16.0419 & 12.1363 & 11.753 & 5.89777 & 3.92801 & 3.5074 & 2.53402 & 1.76347 & 0.9935 \\
\hline 1 & 1 & 2 & 1 & 1 & 1 & 1 & 1 & 1 \\
\hline 570.66 & 0 & 767.89 & 108.57 & 393.23 & 809.12 & 393.23 & 430.90 & 852.87 \\
\hline 754.59 & 263.49 & 1125.63 & 372.06 & 437.28 & 1166.86 & 474.95 & 501.76 & 1210.61 \\
\hline 840.56 & 372.06 & 1166.86 & 413.66 & 474.95 & 1210.61 & 501.76 & 515.16 & 1227.9 \\
\hline 501.76 & 515.16 & 596.99 & 754.59 & 840.56 & 949.71 & 1125.63 & 1166.86 & 1210.61 \\
\hline- & r1 & - & - & $\mathrm{r} 2$ & - & - & r1 & r2 \\
\hline 19,18 & 19 & 19,22 & 22,21 & 23 & 23,24 & 24 & 25 & 26 \\
\hline 18 & 19 & 20 & 21 & 22 & 23 & 24 & 25 & 26 \\
\hline
\end{tabular}

Table 12. ACTRES Scheduling, $R \max =2, \mathrm{n}(\mathrm{r})=2($ Scenario 3$)$ 


\begin{tabular}{|c|c|c|c|c|c|c|c|c|c|}
\hline & 1 & 4 & 19 & 2 & 7 & 8 & 5 & 10 & 9 \\
\hline Duration (second) & 25.70 & 43.56 & 157.60 & 74.20 & 25.97 & 44.4 & 125.96 & 93.37 & 18.47 \\
\hline ACTIM & 1740.32 & 1688.92 & 873.56 & 825.12 & 800.9 & 774.93 & 751.7 & 730.53 & 655.63 \\
\hline Scaled ACTIM & 100 & 97.0465 & 50.1954 & 47.412 & 46.0203 & 44.528 & 43.1587 & 41.9768 & 37.673 \\
\hline Resource required & 2 & 2 & 2 & 1 & 1 & 1 & 1 & 1 & 1 \\
\hline TEARL & 0 & 25.70 & 413.06 & 0 & 69.26 & 95.23 & 74.02 & 139.63 & 139.63 \\
\hline TSCHED & 0 & 25.7 & 442.12 & 0 & 69.26 & 95.23 & 74.02 & 139.63 & 177.83 \\
\hline TFIN & 25.70 & 69.26 & 599.72 & 74.02 & 95.23 & 139.63 & 199.98 & 233 & 196.3 \\
\hline TNOW & 0 & 25.7 & 69.26 & 74.02 & 95.23 & 139.63 & 177.83 & 196.3 & 199.98 \\
\hline Resource available & - & - & - & - & - & - & - & - & $\mathrm{r} 3$ \\
\hline Activities allowed & $1,2,3$ & 4,3 & 7,3 & 5 & 8 & 10,9 & 9,6 & 6 & - \\
\hline Iteration number & 1 & 2 & 3 & 4 & 5 & 6 & 7 & 8 & 9 \\
\hline
\end{tabular}

\begin{tabular}{|r|r|r|r|r|r|r|r|}
\hline 11 & 12 & \multicolumn{1}{c|}{13} & \multicolumn{1}{c|}{17} & \multicolumn{1}{c|}{16} & \multicolumn{1}{c|}{20} & \multicolumn{1}{c|}{23} & \multicolumn{1}{c|}{22} \\
\hline 12.02 & 122.72 & 25.49 & 48.89 & 19.83 & 130.65 & 175.92 & 195.12 \\
\hline 637.16 & 625.14 & 502.42 & 476.93 & 456.61 & 428.04 & 297.39 & 279.18 \\
\hline 36.6117 & 35.921 & 28.8694 & 27.40473 & 26.2371288 & 24.5954767 & 22.204 & 17.0882 \\
\hline 1 & 1 & 1 & 1 & 1 & 1 & 2 & 1 \\
\hline 233.00 & 245.02 & 367.74 & 393.23 & 393.23 & 442.12 & 656.63 & 572.77 \\
\hline 233 & 245.02 & 367.74 & 393.23 & 393.23 & 444.3 & 685.69 & 574.95 \\
\hline 245.02 & 367.74 & 393.23 & 442.12 & 413.06 & 574.95 & 861.61 & 770.07 \\
\hline 233 & 237.9 & 245.02 & 367.74 & 393.23 & 413.06 & 430.9 & 439.87 \\
\hline $\mathrm{r} 1$ & $\mathrm{r} 1, \mathrm{r} 2$ & $\mathrm{r} 1, \mathrm{r} 2$ & $\mathrm{r} 1, \mathrm{r} 3$ & - & - & - & $\mathrm{r} 1$ \\
\hline 11 & - & 12 & 13 & $17,16,15,14$ & 19,14 & 19,18 & 19 \\
\hline 10 & 11 & 12 & 13 & 14 & 15 & 16 & 17 \\
\hline
\end{tabular}

Second Percentage

\begin{tabular}{|l|r|r|}
\hline idler $\mathbf{r} 1$ & 221 & 22.93 \\
\hline idler $\mathbf{r} 2$ & 265.13 & 27.51 \\
\hline idler $\mathbf{r} 3$ & 205.52 & 21.32 \\
\hline
\end{tabular}

\begin{tabular}{|r|r|r|r|r|r|r|r|r|}
\hline \multicolumn{1}{|c|}{3} & \multicolumn{1}{c|}{$\mathbf{2 4}$} & \multicolumn{1}{c|}{$\mathbf{6}$} & \multicolumn{1}{c|}{15} & \multicolumn{1}{c|}{25} & \multicolumn{1}{c|}{14} & \multicolumn{1}{c|}{18} & \multicolumn{1}{c|}{26} \\
\hline 85.97 & 108.57 & 41.23 & 41.6 & 37.67 & 43.75 & 26.81 & 13.40 & 17.29 \\
\hline 279.18 & 211.21 & 204.54 & 102.64 & 68.36 & 61.04 & 44.1 & 30.69 & 17.29 \\
\hline 16.0419 & 12.1363 & 11.753 & 5.89777 & 3.92801 & 3.5074 & 2.53402 & 1.76347 & 0.9935 \\
\hline 1 & 1 & 2 & 1 & 1 & 1 & 1 & 1 & 1 \\
\hline 570.66 & 0 & 767.89 & 108.57 & 393.23 & 809.12 & 393.23 & 430.90 & 852.87 \\
\hline 599.72 & 69.26 & 861.61 & 196.3 & 393.23 & 902.84 & 413.06 & 430.9 & 946.59 \\
\hline 685.69 & 177.83 & 902.84 & 237.9 & 430.9 & 946.59 & 439.87 & 444.3 & 963.88 \\
\hline 442.12 & 444.3 & 574.95 & 599.72 & 685.69 & 770.07 & 861.61 & 902.84 & 946.59 \\
\hline- & - & - & $\mathrm{r} 3$ & - & $\mathrm{r} 2$ & $\mathrm{r} 1$ & $\mathrm{r} 2, \mathrm{r3}$ & $\mathrm{r} 1, \mathrm{r} 3$ \\
\hline 19,20 & 20 & 22 & 21 & 23 & 24 & 24 & 25 & 26 \\
\hline 18 & 19 & 20 & 21 & 22 & 23 & 24 & 25 & 26 \\
\hline
\end{tabular}

Table 13. ACTRES Scheduling, $\operatorname{Rmax}=2, \mathrm{n}(\mathrm{r})=3$ (Scenario 4) 


\begin{tabular}{|l|r|r|r|r|r|r|r|r|r|}
\hline & \multicolumn{1}{|c|}{1} & \multicolumn{1}{c|}{$\mathbf{4}$} & \multicolumn{1}{c|}{$\mathbf{7}$} & \multicolumn{1}{c|}{$\mathbf{8}$} & \multicolumn{1}{c|}{5} & \multicolumn{1}{c|}{10} & 9 & 19 \\
\hline Duration (second) & 25.70 & 43.56 & 74.02 & 25.97 & 44.4 & 125.96 & 93.37 & 18.47 & 157.60 \\
\hline ACTIM & 1305.24 & 1266.69 & 852.12 & 800.90 & 774.93 & 751.10 & 730.53 & 655.63 & 655.17 \\
\hline Scaled ACTIM & 100 & 97.0465 & 63.216 & 61.3604 & 59.3707 & 57.545 & 55.969 & 50.2306 & 50.1954 \\
\hline Resource required & 2 & 2 & 1 & 1 & 1 & 1 & 1 & 1 & 2 \\
\hline TEARL & 0 & 25.70 & 0 & 69.26 & 95.23 & 74.02 & 139.63 & 139.63 & 413.06 \\
\hline TSCHED & 0 & 25.7 & 69.26 & 69.26 & 95.23 & 143.28 & 139.63 & 233 & 596.99 \\
\hline TFIN & 25.7 & 69.26 & 143.28 & 95.23 & 139.63 & 269.24 & 233 & 251.47 & 754.49 \\
\hline TNOW & 0 & 25.7 & 69.26 & 95.23 & 139.63 & 143.28 & 233 & 251.47 & 263.49 \\
\hline Resource available & - & - & - & - & - & - & - & - & - \\
\hline Activities allowed & $1,2,3$ & $4,2,3$ & $2,7,3$ & 8,3 & $10,9,3$ & $5,9,3$ & 9,3 & 11,3 & 3 \\
\hline Iteration number & 1 & 2 & 3 & 4 & 5 & 6 & 7 & 8 & 9 \\
\hline
\end{tabular}

\begin{tabular}{|r|r|r|r|r|r|r|r|}
\hline 11 & 12 & \multicolumn{1}{c|}{13} & \multicolumn{1}{c|}{17} & \multicolumn{1}{c|}{16} & \multicolumn{1}{c|}{20} & \multicolumn{1}{c|}{22} & \multicolumn{1}{c|}{23} \\
\hline 12.02 & 122.72 & 25.49 & 48.89 & 19.83 & 130.65 & 195.12 & 175.92 \\
\hline 637.16 & 625.14 & 502.42 & 476.93 & 456.61 & 428.04 & 297.39 & 289.82 \\
\hline 48.8155 & 47.8946 & 38.4925 & 36.53964 & 34.98283841 & 32.794 & 22.7843 & 22.204 \\
\hline 1 & 1 & 1 & 1 & 1 & 1 & 1 & 2 \\
\hline 233.00 & 245.02 & 367.74 & 393.23 & 393.23 & 442.12 & 572.77 & 656.63 \\
\hline 251.47 & 269.24 & 391.96 & 417.45 & 417.45 & 466.34 & 754.59 & 949.71 \\
\hline 263.49 & 391.96 & 417.45 & 466.34 & 437.28 & 596.99 & 949.71 & 1125.63 \\
\hline 269.24 & 372.06 & 391.96 & 413.66 & 417.45 & 437.28 & 466.34 & 474.95 \\
\hline- & - & - & $\mathrm{r} 2$ & - & - & - & - \\
\hline 12 & 6 & 13 & - & $17,16,15,14$ & $19,15,14$ & $19,20,14$ & $19,14,18$ \\
\hline 10 & 11 & 12 & 13 & 14 & 15 & 16 & 17 \\
\hline
\end{tabular}

\begin{tabular}{|l|r|r|}
\hline & \multicolumn{1}{|c|}{ Second } & Percentage \\
\hline idler r1 & 125.58 & 10.2272172 \\
\hline idler r2 & 130.23 & 10.60591253 \\
\hline
\end{tabular}

\begin{tabular}{|r|r|r|r|r|r|r|r|r|}
\hline \multicolumn{1}{|c|}{3} & \multicolumn{1}{c|}{24} & \multicolumn{1}{c|}{$\mathbf{6}$} & \multicolumn{1}{c|}{15} & \multicolumn{1}{c|}{25} & \multicolumn{1}{c|}{14} & \multicolumn{1}{c|}{18} & \multicolumn{1}{c|}{26} \\
\hline 85.97 & 108.57 & 41.23 & 41.6 & 37.67 & 43.75 & 26.81 & 13.40 & 17.29 \\
\hline 279.18 & 211.21 & 153.41 & 102.64 & 68.36 & 61.04 & 44.10 & 30.69 & 17.29 \\
\hline 21.3892 & 16.1817 & 11.753 & 7.86369 & 5.23735 & 4.67653 & 3.37869 & 2.35129 & 1.32466 \\
\hline 1 & 1 & 2 & 1 & 1 & 1 & 1 & 1 & 1 \\
\hline 570.66 & 0 & 767.89 & 108.57 & 393.23 & 809.12 & 393.23 & 430.90 & 852.87 \\
\hline 754.59 & 263.49 & 1125.63 & 372.06 & 437.28 & 1166.86 & 474.95 & 501.76 & 1210.61 \\
\hline 840.56 & 372.06 & 1166.86 & 413.66 & 474.95 & 1210.61 & 501.76 & 515.16 & 1227.9 \\
\hline 501.76 & 515.16 & 596.99 & 754.59 & 840.56 & 949.71 & 1125.63 & 1166.86 & 1210.61 \\
\hline- & $\mathrm{r} 1$ & - & - & $\mathrm{r} 2$ & - & - & $\mathrm{r} 1$ & $\mathrm{r} 2$ \\
\hline 19,18 & 19 & 19,22 & 22,21 & 23 & 23,24 & 24 & 25 & 26 \\
\hline 18 & 19 & 20 & 21 & 22 & 23 & 24 & 25 & 26 \\
\hline
\end{tabular}

Table 14. TIMRES Scheduling, $R \max =2, \mathrm{n}(\mathrm{r})=2$ (Scenario 3) 


\begin{tabular}{|c|c|c|c|c|c|c|c|c|c|}
\hline & 1 & 4 & 2 & 7 & 8 & 5 & 10 & 9 & 19 \\
\hline Duration (second) & 25.70 & 43.56 & 74.20 & 25.97 & 44.4 & 125.96 & 93.37 & 18.47 & 157.60 \\
\hline ACTIM & 1305.24 & 1266.69 & 825.12 & 800.9 & 774.93 & 751.1 & 730.53 & 655.63 & 655.63 \\
\hline Scaled ACTIM & 100 & 97.0465 & 62.216 & 61.3604 & 59.3707 & 57.545 & 55.969 & 50.2306 & 50.1954 \\
\hline Resource required & 2 & 2 & 1 & 1 & 1 & 1 & 1 & 1 & 2 \\
\hline TEARL & 0 & 25.70 & 0 & 69.26 & 95.23 & 74.02 & 139.63 & 139.63 & 413.06 \\
\hline TSCHED & 0 & 25.7 & 0 & 69.26 & 95.23 & 74.02 & 139.63 & 177.83 & 442.12 \\
\hline TFIN & 25.70 & 69.26 & 74.02 & 95.23 & 139.63 & 199.98 & 233 & 196.3 & 599.72 \\
\hline TNOW & 0 & 25.7 & 69.26 & 74.02 & 95.23 & 139.63 & 177.83 & 196.3 & 199.98 \\
\hline Resource available & - & - & - & - & - & - & - & - & r3 \\
\hline Activities allowed & $1,2,3$ & 4,3 & 7,3 & 5 & 8 & 10,9 & 9,6 & 6 & - \\
\hline Iteration number & 1 & 2 & 3 & 4 & 5 & 6 & 7 & 8 & 9 \\
\hline
\end{tabular}

\begin{tabular}{|r|r|r|r|r|r|r|r|}
\hline 11 & 12 & 13 & 17 & 16 & \multicolumn{1}{c|}{20} & \multicolumn{1}{c|}{22} & \multicolumn{1}{c|}{23} \\
\hline 12.02 & 122.72 & 25.49 & 48.89 & 19.83 & 130.65 & 195.12 & 175.92 \\
\hline 637.16 & 625.14 & 502.42 & 476.93 & 456.61 & 428.04 & 297.39 & 289.82 \\
\hline 48.8155 & 47.8946 & 38.4925 & 36.53964 & 34.98283841 & 32.794 & 22.7843 & 22.204 \\
\hline 1 & 1 & 1 & 1 & 1 & 1 & 1 & 2 \\
\hline 233 & 245.02 & 367.74 & 393.23 & 393.23 & 442.12 & 572.77 & 656.63 \\
\hline 233 & 245.02 & 367.74 & 393.23 & 393.23 & 444.3 & 574.95 & 685.69 \\
\hline 245.02 & 367.74 & 393.23 & 442.12 & 413.06 & 574.95 & 770.07 & 861.61 \\
\hline 233 & 237.9 & 245.02 & 367.74 & 393.23 & 413.06 & 430.9 & 439.87 \\
\hline $\mathrm{r} 1$ & $\mathrm{r} 1, \mathrm{r} 2$ & $\mathrm{r} 1, \mathrm{r} 2$ & $\mathrm{r} 1, \mathrm{r} 3$ & - & - & - & $\mathrm{r} 1$ \\
\hline 11 & - & 12 & 13 & $17,16,15,14$ & 19,14 & 19,18 & 19 \\
\hline 10 & 11 & 12 & 13 & 14 & 15 & 16 & 17 \\
\hline
\end{tabular}

\begin{tabular}{|l|r|r|} 
& Second & Percentage \\
\hline idler $\mathbf{r} 1$ & 221 & 22.93 \\
\hline idler $\mathbf{r} 2$ & 265.13 & 27.51 \\
\hline
\end{tabular}

\begin{tabular}{|r|r|r|r|r|r|r|r|r|}
\hline \multicolumn{1}{|c|}{3} & \multicolumn{1}{c|}{ 24 } & \multicolumn{1}{c|}{6} & \multicolumn{1}{c|}{15} & \multicolumn{1}{c|}{25} & \multicolumn{1}{c|}{14} & \multicolumn{1}{c|}{18} & \multicolumn{1}{c|}{26} \\
\hline 85.97 & 108.57 & 41.23 & 41.6 & 37.67 & 43.75 & 26.81 & 13.40 & 17.29 \\
\hline 279.18 & 211.21 & 153.41 & 102.64 & 68.36 & 61.04 & 44.1 & 30.69 & 17.29 \\
\hline 21.3892 & 16.1817 & 11.753 & 7.86369 & 5.23735 & 4.67653 & 3.37869 & 2.35129 & 1.32466 \\
\hline 1 & 1 & 2 & 1 & 1 & 1 & 1 & 1 & 1 \\
\hline 570.66 & 0 & 767.89 & 108.57 & 393.23 & 809.12 & 393.23 & 430.90 & 852.87 \\
\hline 599.72 & 69.26 & 861.61 & 196.3 & 393.23 & 902.84 & 413.06 & 430.9 & 946.59 \\
\hline 685.69 & 177.83 & 902.84 & 237.9 & 430.9 & 946.59 & 439.87 & 444.3 & 963.88 \\
\hline 442.12 & 444.3 & 574.95 & 599.72 & 685.69 & 770.07 & 861.61 & 902.84 & 946.59 \\
\hline- & - & - & $\mathrm{r} 3$ & - & $\mathrm{r} 2$ & $\mathrm{r} 1$ & $\mathrm{r} 2, \mathrm{r} 3$ & $\mathrm{r} 1, \mathrm{r} 3$ \\
\hline 19,20 & 20 & 22 & 21 & 23 & 24 & 24 & 25 & 26 \\
\hline 18 & 19 & 20 & 21 & 22 & 23 & 24 & 25 & 26 \\
\hline
\end{tabular}

Table 15. TIMRES Scheduling, $R \max =2, \mathrm{n}(\mathrm{r})=3$ (Scenario 4) 


\begin{tabular}{|c|c|c|c|c|c|c|c|c|c|}
\hline & 1 & 4 & 2 & 7 & 8 & 5 & 10 & 9 & 11 \\
\hline Duration (second) & 17.13 & 29.04 & 74.02 & 25.97 & 44.4 & 125.96 & 93.37 & 18.47 & 12.02 \\
\hline ACTIM & 847.07 & 829.94 & 825.12 & 800.90 & 774.93 & 751.10 & 730.53 & 655.63 & 637.16 \\
\hline Scaled ACTIM & 100 & 97.9777 & 97.4087 & 94.5494 & 91.4836 & 88.6704 & 86.242 & 77.3997 & 75.2193 \\
\hline Resource required & 3 & 3 & 1 & 1 & 1 & 1 & 1 & 1 & 1 \\
\hline TEARL & 0 & 17.13 & 0 & 46.17 & 72.14 & 74.02 & 116.54 & 116.54 & 209.91 \\
\hline TSCHED & 0 & 17.13 & 46.17 & 46.17 & 72.14 & 120.19 & 116.54 & 154.74 & 209.91 \\
\hline TFIN & 17.13 & 46.17 & 120.19 & 72.14 & 116.54 & 246.15 & 209.91 & 173.21 & 221.93 \\
\hline TNOW & 0 & 17.13 & 46.17 & 72.14 & 116.54 & 120.19 & 154.74 & 173.21 & 209.91 \\
\hline Resource available & - & - & - & - & - & - & - & - & - \\
\hline Activities allowed & $1,2,3$ & $4,2,3$ & $2,7,3$ & 8 & 10,9 & 5,9 & 9,6 & 6 & 11 \\
\hline Iteration number & 1 & 2 & 3 & 4 & 5 & 6 & 7 & 8 & 9 \\
\hline
\end{tabular}

\begin{tabular}{|c|c|c|c|c|c|c|c|}
\hline 12 & 13 & 17 & 20 & 16 & 19 & 22 & 21 \\
\hline 122.72 & 25.49 & 48.89 & 130.65 & 19.83 & 105.07 & 195.12 & 85.97 \\
\hline 625.14 & 502.42 & 476.93 & 428.04 & 404.08 & 384.25 & 297.39 & 279.18 \\
\hline 73.8003 & 59.3127 & 56.3035 & 50.531833 & 47.70325947 & 45.3622 & 35.1081 & 32.9583 \\
\hline 1 & 1 & 1 & 1 & 1 & 3 & 1 & 1 \\
\hline 221.93 & 344.65 & 370.14 & 419.03 & 370.14 & 389.97 & 549.68 & 495.04 \\
\hline 246.15 & 368.87 & 394.36 & 443.25 & 394.36 & 573.9 & 678.97 & 678.97 \\
\hline 368.87 & 394.36 & 443.25 & 573.9 & 414.19 & 678.97 & 874.09 & 764.94 \\
\hline 214.81 & 221.93 & 246.15 & 368.87 & 394.36 & 41.19 & 432.03 & 441 \\
\hline $\mathrm{r} 3$ & $\mathrm{r} 2, \mathrm{r} 3$ & $\mathrm{r} 1, \mathrm{r} 2$ & $\mathrm{r} 1, \mathrm{r} 3$ & - & - & - & r3 \\
\hline- & - & 12 & 13 & $17,16,15,14$ & 19,14 & 19,18 & 19 \\
\hline 10 & 11 & 12 & 13 & 14 & 15 & 16 & 17 \\
\hline & & & Second & Percentage & & & \\
\hline & & idler r1 & 295.22 & 28.30 & & & \\
\hline & & idler $\mathrm{r} 2$ & 333.93 & 32.01 & & & \\
\hline & & idler r3 & 300.25 & 28.78 & & & \\
\hline
\end{tabular}

\begin{tabular}{|r|r|r|r|r|r|r|r|r|}
\hline \multicolumn{1}{|c|}{$\mathbf{3}$} & \multicolumn{1}{c|}{$\mathbf{2 3}$} & \multicolumn{1}{c|}{$\mathbf{2 4}$} & \multicolumn{1}{c|}{$\mathbf{1 5}$} & \multicolumn{1}{c|}{25} & \multicolumn{1}{c|}{14} & \multicolumn{1}{c|}{18} & \multicolumn{1}{c|}{26} \\
\hline 108.57 & 175.92 & 41.6 & 41.23 & 37.67 & 43.75 & 26.81 & 13.40 & 17.29 \\
\hline 211.21 & 193.21 & 102.64 & 102.64 & 68.36 & 61.04 & 44.10 & 30.69 & 17.29 \\
\hline 24.9342 & 22.8092 & 12.1171 & 12.0734 & 8.07017 & 7.20602 & 5.20618 & 3.62308 & 2.041154 \\
\hline 1 & 2 & 1 & 2 & 1 & 1 & 1 & 1 & 1 \\
\hline 0 & 581.01 & 108.57 & 744.80 & 370.14 & 786.03 & 370.14 & 407.81 & 829.78 \\
\hline 46.17 & 764.94 & 173.21 & 940.86 & 394.36 & 982.09 & 414.19 & 432.03 & 1025.84 \\
\hline 154.74 & 940.86 & 214.81 & 982.09 & 432.03 & 1025.84 & 441 & 445.45 & 1034.13 \\
\hline 443.25 & 445.43 & 573.9 & 678.97 & 764.94 & 874.09 & 940.86 & 982.09 & 1025.84 \\
\hline $\mathrm{r} 3$ & $\mathrm{r} 2, \mathrm{r} 3$ & - & $\mathrm{r} 1$ & - & $\mathrm{r} 3$ & $\mathrm{r} 2$ & $\mathrm{r} 1, \mathrm{r3}$ & $\mathrm{r} 1, \mathrm{r} 2$ \\
\hline 19,20 & 19 & 19,22 & 22,21 & 23 & 24 & 24 & 25 & 26 \\
\hline 18 & 19 & 20 & 21 & 22 & 23 & 24 & 25 & 26 \\
\hline
\end{tabular}

Table 16. ACTIM Scheduling, $R \max =3, \mathrm{n}(\mathrm{r})=3$ (Scenario 5) 


\begin{tabular}{|c|c|c|c|c|c|c|c|c|c|}
\hline & 1 & 4 & 19 & 2 & 7 & 8 & 5 & 10 & 9 \\
\hline Duration (second) & 17.13 & 29.04 & 105.07 & 74.02 & 25.97 & 44.4 & 125.96 & 93.37 & 18.47 \\
\hline ACTIM & 2541.21 & 2489.82 & 1152.75 & 825.12 & 800.9 & 774.93 & 751.1 & 730.53 & 655.63 \\
\hline Scaled ACTIM & 100 & 97.9777 & 45.3622 & 32.4696 & 31.5165 & 30.4945 & 29.5568 & 28.7473 & 25.7999 \\
\hline Resource required & 3 & 3 & 3 & 1 & 1 & 1 & 1 & 1 & 2 \\
\hline TEARL & 0 & 17.13 & 389.97 & 0 & 46.17 & 72.14 & 74.02 & 116.54 & 116.54 \\
\hline TSCHED & 0 & 17.13 & 573.9 & 46.17 & 46.17 & 72.14 & 120.19 & 116.54 & 154.74 \\
\hline TFIN & 17.13 & 46.17 & 678.97 & 120.19 & 72.14 & 116.54 & 246.15 & 209.92 & 173.21 \\
\hline TNOW & 0 & 17.13 & 46.17 & 72.14 & 116.54 & 120.19 & 154.74 & 173.21 & 209.91 \\
\hline Resource available & - & - & - & - & - & - & - & - & - \\
\hline Activities allowed & $1,2,3$ & $4,2,3$ & $2,7,3$ & 8 & 10,9 & 5,9 & 9,6 & 6 & 11 \\
\hline Iteration number & 1 & 2 & 3 & 4 & 5 & 6 & 7 & 8 & 9 \\
\hline
\end{tabular}

\begin{tabular}{|r|r|r|r|r|r|r|r|}
\hline 11 & 12 & 13 & 17 & \multicolumn{1}{c|}{20} & \multicolumn{1}{c|}{16} & \multicolumn{1}{c|}{23} & \multicolumn{1}{c|}{22} \\
\hline 12.02 & 122.72 & 25.49 & 48.89 & 130.65 & 19.83 & 175.92 & 195.5 .12 \\
\hline 637.16 & 625.14 & 502.42 & 476.93 & 428.04 & 404.08 & 386.42 & 297.18 \\
\hline 25.0731 & 24.6001 & 19.7709 & 18.767831 & 16.84394442 & 15.9011 & 15.2061 & 11.7027 \\
\hline 1 & 1 & 1 & 1 & 1 & 1 & 2 & 1 \\
\hline 209.91 & 221.93 & 344.65 & 370.14 & 419.03 & 370.14 & 581.001 & 549.68 \\
\hline 209.91 & 246.15 & 368.87 & 394.36 & 443.25 & 394.36 & 764.94 & 678.97 \\
\hline 221.93 & 368.87 & 394.36 & 443.25 & 573.9 & 414.19 & 940.86 & 874.09 \\
\hline 214.81 & 221.93 & 246.15 & 368.87 & 394.36 & 414.19 & 432.03 & 441 \\
\hline $\mathrm{r} 3$ & $\mathrm{r} 2, \mathrm{r} 3$ & $\mathrm{r} 1, \mathrm{r} 2$ & $\mathrm{r} 1, \mathrm{r} 3$ & - & - & - & $\mathrm{r} 3$ \\
\hline- & - & 12 & 13 & $17,16,15,14$ & 19,14 & 19,18 & 19 \\
\hline 10 & 11 & 12 & 13 & 14 & 15 & 16 & 17 \\
\hline
\end{tabular}

Second Percentage

\begin{tabular}{|l|l|l|}
\hline idler $\mathbf{r} 1$ & 295.22 & 28.30 \\
\hline idler $\mathbf{r}$ & 333.93 & 32.01 \\
\hline idler $\mathbf{r} 3$ & 300.25 & 28.78 \\
\hline
\end{tabular}

\begin{tabular}{|r|r|r|r|r|r|r|r|r|}
\hline \multicolumn{1}{|c|}{3} & \multicolumn{1}{c|}{$\mathbf{2 4}$} & \multicolumn{1}{c|}{$\mathbf{6}$} & \multicolumn{1}{c|}{15} & \multicolumn{1}{c|}{25} & \multicolumn{1}{c|}{14} & \multicolumn{1}{c|}{18} & \multicolumn{1}{c|}{26} \\
\hline 85.97 & 108.57 & 41.23 & 41.6 & 37.67 & 43.75 & 26.81 & 13.40 & 17.29 \\
\hline 279.18 & 211.21 & 204.54 & 102.64 & 68.36 & 61.04 & 44.1 & 30.69 & 17.29 \\
\hline 10.9861 & 8.31139 & 8.04892 & 4.03902 & 2.69006 & 2.40201 & 1.73539 & 1.20769 & 0.68038 \\
\hline 1 & 1 & 2 & 1 & 1 & 1 & 1 & 1 & 1 \\
\hline 495.04 & 0 & 744.80 & 108.57 & 370.14 & 786.03 & 370.14 & 407.81 & 829.78 \\
\hline 678.97 & 46.17 & 940.86 & 173.21 & 394.36 & 982.09 & 414.19 & 432.03 & 1025.84 \\
\hline 764.94 & 154.74 & 982.09 & 214.81 & 432.03 & 1025.84 & 441 & 445.43 & 1043.13 \\
\hline 443.25 & 445.43 & 573.9 & 678.97 & 764.94 & 874.09 & 940.86 & 982.09 & 1025.84 \\
\hline $\mathrm{r} 3$ & $\mathrm{r} 2, \mathrm{r} 3$ & - & $\mathrm{r} 1$ & - & $\mathrm{r} 3$ & $\mathrm{r} 2$ & $\mathrm{r} 1, \mathrm{r} 3$ & $\mathrm{r} 1, \mathrm{r} 2$ \\
\hline 19,20 & 19 & 19,22 & 22,21 & 23 & 24 & 24 & 25 & 26 \\
\hline 18 & 19 & 20 & 21 & 22 & 23 & 24 & 25 & 26 \\
\hline
\end{tabular}

Table 17. ACTRES Scheduling, $R \max =3, n(r)=3$ (Scenario 5) 


\begin{tabular}{|c|c|c|c|c|c|c|c|c|c|}
\hline & 1 & 4 & 2 & 7 & 8 & 19 & 5 & 10 & 9 \\
\hline Duration (second) & 17.13 & 29.04 & 74.02 & 25.97 & 44.4 & 105.07 & 125.96 & 93.37 & 18.47 \\
\hline ACTIM & 1694.14 & 1659.88 & 825.12 & 800.90 & 774.93 & 768.50 & 751.10 & 730.53 & 655.63 \\
\hline Scaled ACTIM & 100 & 97.9777 & 48.7044 & 47.2747 & 45.7418 & 45.3622 & 44.3352 & 43.121 & 38.6999 \\
\hline Resource required & 3 & 3 & 1 & 1 & 1 & 3 & 1 & 1 & 1 \\
\hline TEARL & 0 & 17.13 & 0 & 46.17 & 72.14 & 389.97 & 74.02 & 116.54 & 116.54 \\
\hline TSCHED & 0 & 17.13 & 46.17 & 46.17 & 72.14 & 573.9 & 120.19 & 116.54 & 154.74 \\
\hline TFIN & 17.13 & 46.17 & 120.19 & 72.14 & 116.54 & 678.97 & 246.15 & 209.91 & 173.21 \\
\hline TNOW & 0 & 17.13 & 46.17 & 72.14 & 116.54 & 120.19 & 154.74 & 173.21 & 209.91 \\
\hline Resource available & - & - & - & - & - & - & - & - & - \\
\hline Activities allowed & $1,2,3$ & $4,2,3$ & $2,7,3$ & 8 & 10,9 & 5,9 & 9,6 & 6 & 11 \\
\hline Iteration number & 1 & 2 & 3 & 4 & 5 & 6 & 7 & 8 & 9 \\
\hline
\end{tabular}

\begin{tabular}{|r|r|r|r|r|r|r|r|}
\hline 11 & 12 & \multicolumn{1}{|c|}{13} & \multicolumn{1}{c|}{17} & \multicolumn{1}{c|}{20} & \multicolumn{1}{c|}{16} & \multicolumn{1}{c|}{22} & \multicolumn{1}{c|}{23} \\
\hline 12.02 & 122.72 & 25.49 & 48.89 & 130.65 & 19.83 & 195.12 & 175.92 \\
\hline 637.17 & 625.14 & $502.14,502.42$ & 476.93 & 428.04 & 404.08 & 297.39 & 289.82 \\
\hline 37.6096 & 36.9001 & 29.6563 & 28.151747 & 25.26591883 & 23.8516 & 17.554 & 17.1069 \\
\hline 1 & 1 & 1 & 1 & 1 & 1 & 1 & 2 \\
\hline 209.91 & 221.93 & 344.65 & 370.14 & 419.03 & 370.14 & 549.68 & 581.01 \\
\hline 209.91 & 246.15 & 368.87 & 394.36 & 443.25 & 394.36 & 678.97 & 764.94 \\
\hline 221.93 & 368.87 & 394.36 & 443.25 & 573.9 & 414.19 & 874.09 & 940.86 \\
\hline 214.81 & 221.93 & 246.15 & 368.87 & 394.36 & 41.19 & 432.03 & 441 \\
\hline $\mathrm{r} 3$ & $\mathrm{r} 2, \mathrm{r} 3$ & $\mathrm{r} 1, \mathrm{r} 2$ & $\mathrm{r} 1, \mathrm{r} 3$ & - & - & - & $\mathrm{r} 3$ \\
\hline- & - & 12 & 13 & $17,16,15,14$ & 19,14 & 19,18 & 19 \\
\hline 10 & 11 & 12 & 13 & 14 & 15 & 16 & 17 \\
\hline
\end{tabular}

\section{Second Percentage}

\begin{tabular}{|l|l|l|}
\hline idler r1 & 295.22 & 28.30 \\
\hline idler r $\mathbf{2}$ & 333.93 & 32.01 \\
\hline idler r3 & 300.25 & 28.78 \\
\hline
\end{tabular}

\begin{tabular}{|r|r|r|r|r|r|r|r|r|}
\hline \multicolumn{1}{|c|}{3} & \multicolumn{1}{c|}{$\mathbf{2 4}$} & \multicolumn{1}{c|}{$\mathbf{6}$} & \multicolumn{1}{c|}{15} & \multicolumn{1}{c|}{25} & \multicolumn{1}{c|}{14} & \multicolumn{1}{c|}{18} & \multicolumn{1}{c|}{26} \\
\hline 85.97 & 108.57 & 41.23 & 41.6 & 37.67 & 43.75 & 26.81 & 13.40 & 17.29 \\
\hline 279.18 & 211.21 & 153.41 & 102.64 & 68.36 & 61.04 & 44.10 & 30.69 & 17.29 \\
\hline 16.4792 & 12.4671 & 9.05504 & 6.05853 & 4.03509 & 3.60301 & 2.60309 & 1.81154 & 1.02058 \\
\hline 1 & 1 & 2 & 1 & 1 & 1 & 1 & 1 & 1 \\
\hline 495.04 & 0 & 744.80 & 108.57 & 370.14 & 786.03 & 370.14 & 407.81 & 829.78 \\
\hline 678.97 & 46.17 & 940.86 & 173.21 & 394.36 & 982.09 & 414.19 & 432.03 & 1025.13 \\
\hline 764.94 & 154.74 & 982.09 & 214.81 & 432.03 & 1025.84 & 441 & 445.45 & 1043.13 \\
\hline 443.25 & 445.43 & 573.9 & 678.97 & 764.94 & 874.09 & 940.86 & 982.09 & 1025.84 \\
\hline $\mathrm{r} 3$ & $\mathrm{r} 2, \mathrm{r} 3$ & - & $\mathrm{r} 1$ & - & $\mathrm{r} 3$ & $\mathrm{r} 2$ & $\mathrm{r} 1, \mathrm{r} 3$ & $\mathrm{r} 1, \mathrm{r} 2$ \\
\hline 19,20 & 19 & 19,22 & 22,21 & 23 & 24 & 24 & 25 & 26 \\
\hline 18 & 19 & 20 & 21 & 22 & 23 & 24 & 25 & 26 \\
\hline
\end{tabular}

Table 18. TIMRES Scheduling, $R \max =3, \mathrm{n}(\mathrm{r})=3$ (Scenario 5) 


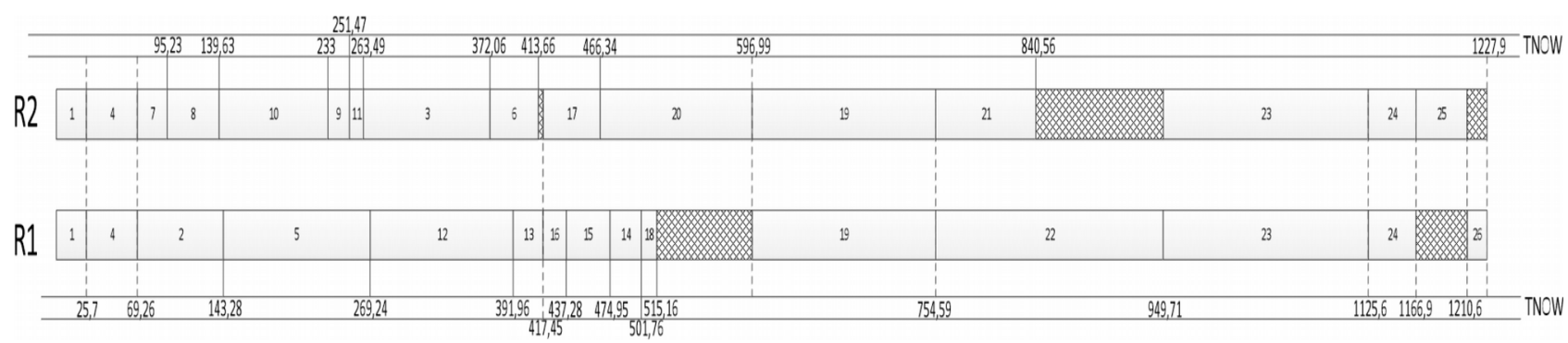

Figure 12. Gantt Chart for the ACTIM, ACTRES, dan TIMRES Scheduling (Scenario 3)

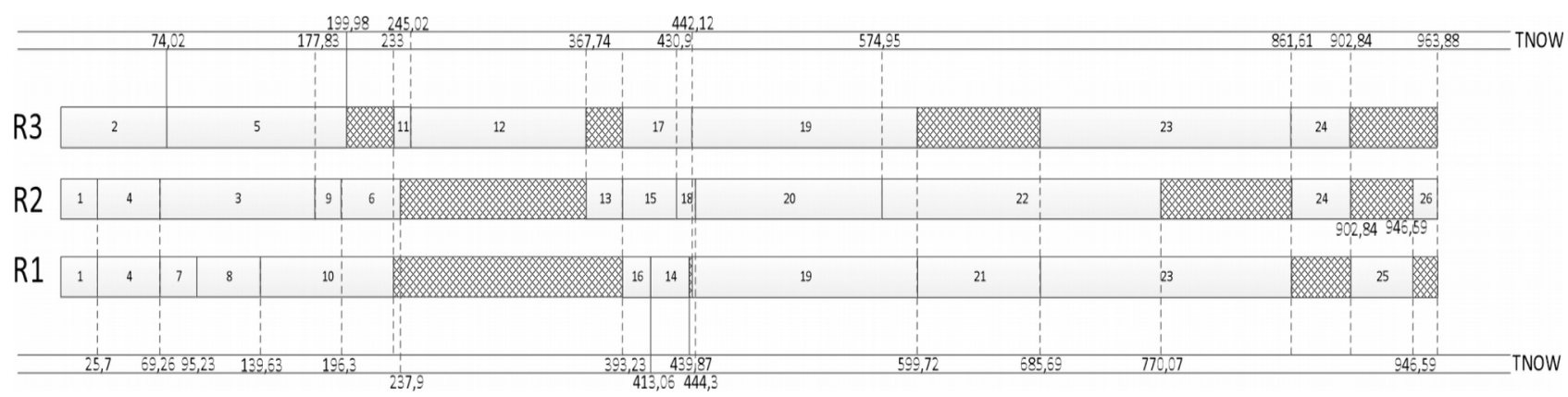

Figure 13. Gantt Chart for the ACTIM, ACTRES, dan TIMRES Scheduling (Scenario 4)

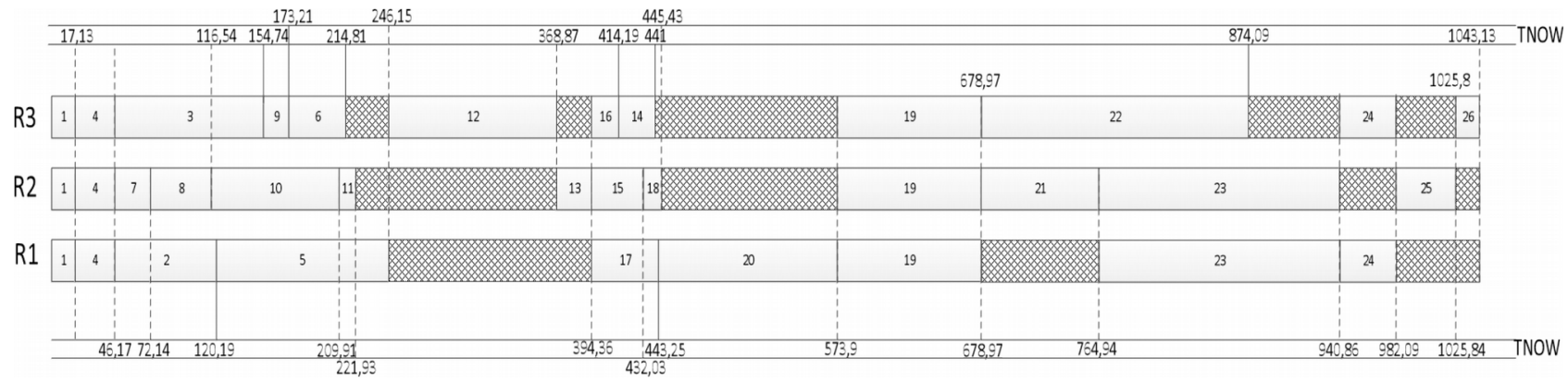

Figure 14. Gantt Chart for the ACTIM, ACTRES, dan TIMRES Scheduling (Scenario 5)

The scheduling obtained from the ACTIM, ACTRES, and TIMRES rule yield the similiar completion time (Cmax) and assignment of work element for each scenario. For the scenario where the maximum number of resource required for each work element is 2 people $(R \max =2)$ and number of people being assigned is 2 per assembly unit, the value of $\mathrm{Cmax}$ is 1227,9 seconds. For the scenario with $\mathrm{Rmax}=2$ and $\mathrm{n}(\mathrm{r})=3$, the Cmax value is 963,88 seconds. While for the scenario with $R \max =3$ and $n(r)=3$, the Cmax value is 1043,1 seconds.

\subsection{Simulation Approach to Assess the Scheduling Performance for Each Scenario}

Because of the application of ACTIM, ACTRES, and TIMRES rule yield the same scheduling result, therefore in this simulation approach, the scheduling result only consist of 5 scenarios, those are:

1. Scenario 1, where the maximum number of resource required for each work element (Rmax) is 1 person, and 2 people being assigned per assembly unit.

2. Scenario 2, where the maximum number of resource required for each work element (Rmax) is 1 person, and 3 people being assigned per assembly unit.

3. Scenario 3, where the maximum number of resource required for each work element (Rmax) is 2 people, and 2 people being assigned per assembly unit.

4. Scenario 4, where the maximum number of resource required for each work element (Rmax) is 2 people, and 3 people being assigned per assembly unit.

5. Scenario 5, where the maximum number of resource required for each work element (Rmax) is 3 people, and 3 people being assigned per assembly unit. 
To know whether those scenarios would overcome the demand, therefore the calculation of production rate per hour is needed to assess each of the scenario performance. Based on the company report, the average cycle time for the metal works process (fabrication of cabinet box) is 9823,91 seconds (2,73 hours). While the cabinet box is being manufactured, the main base for assembly of the electrical circuit is also manufactured, therefore when a batch of 40 units' cabinet box is accomplished. It is brought along with the particular number of electrical circuit main base (the amount is based on the customer order, unlike the cabinet box) to the painting area. The painting process takes around 3 days. After the painting process, the electrical circuit main base can be used for the assembly process.

Moreover, the manufacture of the switchboard has the average deadline of 1 month after the order placement, according to the interview conducted with the Head of Assembly Department. Considering the quantity of order variation, the number of resource being assigned will be adjusted to that quantity order, by hiring the contract employee if it is predicted that the current number of employee isn't adequate to meet the demand.

Based on the last year (2015) demand, the cycle time of the metal works process (CT1), and cycle time of the painting process (CT2), the Author could calculate the TAKT time as the following.

For the high demand rate of 700 units/ month (based on Company report):

$$
\begin{aligned}
\text { TAKT } & =\frac{\text { Available time per month }}{\text { demand per month }} \\
& =\frac{\text { work hour } / \text { mont } \text {-CT } 1-C T 2}{\text { demand per month }} \\
& =\frac{7 \times 26-40 \times 2,73-3 \times 7}{700} \text { hour } \\
& =\frac{182-109.2-21}{700} \text { hour } \\
& =\frac{51,8}{700}=0.074 \text { hour }=4,44 \text { minutes }
\end{aligned}
$$

To be able to meet the demand of 700 units per month, therefore the production rate has to be set so that the product can be released at least every 4,44 minutes.

For the average demand rate of 111 units/month (based on Company report):

$$
\begin{aligned}
\text { TAKT } & =\frac{7 \times 26-40 \times 2,73-3 \times 7}{111} \text { hour } \\
& =\frac{51,8}{111} \text { hour } \\
& =0,467 \text { hours } \\
& =28,02 \text { minutes }
\end{aligned}
$$

Whilst for the low demand rate (50 units), there is no need to make a calculation, because the low seasonal period can be handled within 1 month based on the Cmax obtained for each scheduling.

\subsection{Comparing the Proposed System and Existing System}

Based on the observation conducted to the existing condition, the assembly process of PHB-TR 252 electrical circuit still doesn't have the standard work instruction that is systematically written. The execution of those activities does not follow any rule, and every worker freely specify the next activity that will be performed. This turns out to be inefficient, caused by several factors, those are: 
1. The worker often assists the other worker's task. It eventually causes waste to takes place, when the task's characteristic isn't suitable performed by more than one person. Besides, the worker could be allocated to another pending activity.

2. Some of the particular task could cause the blocking activity that obstruct the completion of other activities. Therefore, it is needed to develop the precedence diagram. So that, it will be known which of the activities that could be done simultaneously with others activities.

3. The absent of the job specialization had caused the worker typically had a well understanding at every work element composing the assembly process. It is instead will not increasing the productivity. Citing the term of labor division, that was applied by Henry Ford at the car assembly area, the division of task for each resource instead will increase the productivity. Worker specialization could increase the productivity by developing a very good skill at each simple activity, compared with the skill at all the process but doesn't has good performance in the execution of each process.

Preliminary study had been done by the concerned company to discover the existing system performance, where the result is 9 workers involved had yield 4 units' assemblies for 50,5 minutes. This data is used as the reference for improvement.

The following table summarize the information gathered by simulation method, that is the performance for each scenario. The parameter being assessed are resource utilization, product departure time, number of worker required, and product output.

\begin{tabular}{|l|r|r|r|r|r|}
\hline & Scenario 1 & Scenario 2 & Scenario 3 & Scenario 4 & Scenario 5 \\
\hline Product departure with 6 workers & 6.44 & 7.63 & 6.91 & 7.14 & 7.14 \\
\hline Product output with 6 workers & 482.50 & 406 & 449 & 435 & 435 \\
\hline \% utilization of resource 1 (high demand rate) & 78.8 & 85.09 & 82.5 & 92.65 & 69.94 \\
\hline \%utilization of resource 2 (high demand rate) & 86.03 & 60.79 & 82.12 & 87.09 & 66.46 \\
\hline \%utilization of resource 3 (high demand rate) & - & 58.01 & - & 94.69 & 69.6 \\
\hline Resource required (high demand rate) & 10 people & 12 people & 10 people & 9 people & 12 people \\
\hline \%utilization of resource 1 (average demand) & 62.78 & 54.02 & 65.54 & 44.44 & 44.54 \\
\hline \%utilization of resource 2 (average demand) & 68.19 & 38.69 & 65.41 & 41.41 & 42.14 \\
\hline \%utilization of resource 3 (average demand) & - & 36.81 & - & 45.11 & 44.24 \\
\hline Resource required (average demand) & 2 people & 3 people & 2 people & 3 people & 3 people \\
\hline
\end{tabular}

Table 19. Performance for Each Improvement Scenario

For the average demand rate, the scenario 1 and scenario 3 tend to yield better performance. Where for scenario 1 and 3, number of resource being assigned for each assembly unit is 2 people. While for scenario 2, 4, and 5, number of worker being assigned are 3 people. For the high demand rate, scenario 4 yields the best performance. However, all the scenarios provided eventually better than the existing system. Because in the existing system, by using 9 workers for the duration 50,5 minute, it only yields 4 assemblies. Therefore, the product departure time is $50,5 / 4=12,625$ minutes.

In the existing condition, workers are not required to complete 1 assembly unit before continue to the next assembly, rather they are more likely to adapt the batch system. Every work element is done for every unit provided in the assembly table, before they can continue to the next work element (Process focus). The proposed system contradicts it, every unit must complete all the work elements, before assembling the next unit (Product focus).

Based on the existing system performance, the product departure time is 12,625 minutes, where this value is obtained if the number of worker is 9 people. If this value is compared with the demand rate/TAKT time for the high demand rate of 700 units, that is 4.44 minutes. Then if the worker is doubled to 18 people, the product departure is only $12,625 / 2=6,313$ minutes. It shows that the demand still can't be fulfilled, if the 
TAKT time for the high demand rate less than the product departure time. Therefore, the number of worker in assembly department that is only 12 people, often caused the company to choose the backorder option, hire more contract employee, and apply the overtime policy to the permanent employee. However, if we use the improvement scenarios, even in regards to overcome the high demand rate, the maximum workers needed is only 12 people, those are on scenario 2 and 5 . For the other scenarios, scenario 1,3, and 4, only need less than 12 workers for the high demand rate. Therefore, there is no need for the overtime policy, additional worker, as well as backorder policy to be conducted.

Moreover, other improvement can be obtained from this research is the omission of the WIP inventory. By adapting the proposed scenario, the procedure is to complete every work elements for each assembly unit before begin to the next assembly. It is done in order to immediately process the assemblies and reduce the WIP inventory. Changing the batch production system into per unit processing, also automatically can reduce the movement of worker.

\section{Conclusion and Recommendation}

\subsection{Conclusion}

Based on the analysis and discussion, the Author can draw several conclusions, those are:

1. For the PHB-TR 252 assembly process, several issues take place, between them are the absent of the written standard work instruction about the sequence of the activity and work element allocation for each resource, therefore causes inefficiency. Proven by the existing system product departure time of 12,625 minutes, where it uses 9 people. Besides, the company often had to choose the backorder option, apply the overtime policy, and hire the contract employee for particular time especially in the high demand rate

2. The sequence of the activity assigned to each of the resource based on scenario 1,3, and 4 (yield better performance) using the resource-constrained project scheduling method are shown by the table below.

\begin{tabular}{|c|c|l|}
\hline Scenario & Resource Type & \multicolumn{1}{|c|}{ Work Element } \\
\hline \multirow{2}{*}{ Scenario 1 } & Resource 1 & $1,4,7,8,10,9,11,12,17,20,22,24,15,25,14,18,26$ \\
\cline { 2 - 3 } & Resource 2 & $2,5,3,6,13,16,19,21,23$ \\
\hline \multirow{2}{*}{ Scenario 3 } & Resource 1 & $1,4,2,5,12,13,16,15,14,18,19,22,23,24,26$ \\
\cline { 2 - 3 } & Resource 2 & $1,4,7,8,10,9,11,3,6,17,20,19,21,23,24,25$ \\
\hline \multirow{3}{*}{ Scenario 4 } & Resource 1 & $1,4,7,8,10,16,14,19,21,23,25$ \\
\cline { 2 - 3 } & Resource 2 & $1,4,3,9,6,13,15,18,20,22,24,26$ \\
\cline { 2 - 3 } & Resource 3 & $2,5,11,12,17,19,23,24$ \\
\hline
\end{tabular}

Table 20. Work Element Assignment for Scenario 1,3, and 4

3. There are 5 improvement scenarios that being proposed by the Author to schedule and sort the work element for each resource available. The performance of these scenario is shown by Table 19 that already being discussed in the previous section. The product departure time, worker utilization, and idle rate for each scenario is also provided on the Table 19. Based on these parameter, scenario 1 and 3 are chosen for the average demand rate, while scenario 4 is chosen for the high demand rate. 


\subsection{Recommendation}

Several recommendations for the future research and for the concerned company are:

1. The improvement at the assembly department must be done simultaneously with the other department, such as metal works department, wiring department, and so on. This is important, because if only one department is improved but the other department is still lacking of attention, the improvement result can only affect the related department. Yet it has an insignificant effect for the whole system.

2. The application of scheduling using RCPS can be converted into the work instruction and the further research could be conducted at the product other than PHB-TR 252.

\section{Declaration of Conflicting Interests}

The authors declared no potential conflicts of interest with respect to the research, authorship, and/or publication of this article.

\section{Funding}

The authors received no financial support for the research, authorship, and/or publication of this article.

\section{References}

Abello, M.B., \& Michalewicz, Z. (2014). Multiobjective Resource-Constrained Project Scheduling with a Time-Varying of Tasks. The Scientific World Journal, 2014, 1-36.

Adnan, A.N., Arbaai, N.A., \& Ismail, A. (2016). Improvement of Overall Efficiency of Production Line By Using Line Balancing. ARPN Journal of Engineering and Applied Sciences, 11(2), 7752-7758.

Agrawal. A., Harhalakis G., Minis I., \& Nagi, R. (1996). Just-in-time production of large assemblies. IIE Transactions Journal, 28(8), 653-667.

Alharkan, I.M. (2011). Algorithm for sequencing and scheduling. Industrial Engineering, Department College of Engineering, King Saud University, Riyadh, Saudi Arabia.

Badiru, A.B. (1996). Project management in manufacturing and high technology operation. New York: John Willey \& Sons.

Haragovich, M., \& Miscey, P. (2014). A Novel Application of Energy Analysis: Lean Manufacturing Tool to Improve Energy Efficiency and Flexibility of Hydrocarbon Processing. Energy, 77, 382-390.

Kolisch, R. (2006). Just-in-time production of large assemblies using project scheduling models and methods. Perspective on Operation Research, Klaus Neumann's Research, 211-224.

Markus, A., Vancza, J., Kis, T., \& Kovacs A. (2003). Project scheduling approach to production planning. Computer and Automation Research Institute, Hungarian Academy of Sciences, Faculty of Electrical Engineering and Informatics, Budapest University of Technology and Economics, Budapest, Hungary.

Naveen, B., \& Babu, T.R. (2015). Productivity Improvement in Manufacturing Industry Using Industrial Engineering Tools. IOSR Journal of Mechanical and Civil Engineering, 3(2), 11-18.

Whitehouse, G., \& Brown, J. (1979). GENRES: An Extension of Brooks algorithm for project scheduling with resource constraints. Computers \& Industrial Engineering, 3, 261-268.

World Bank. (2015). World Development Report. Retrieved from http://www.worldbank.org

Journal of Industrial Engineering and Management, 2018 (www.jiem.org)

(ब)

SOMIE FIEHIS RESEFVIVD

Article's contents are provided on an Attribution-Non Commercial 4.0 Creative commons International License. Readers are allowed to copy, distribute and communicate article's contents, provided the author's and Journal of Industrial Engineering and Management's names are included. It must not be used for commercial purposes. To see the complete license contents, please visit http://creativecommons.org/licenses/by-nc/4.0/. 